Article

\title{
Energy of Intramolecular Hydrogen Bonding in ortho-Hydroxybenzaldehydes, Phenones and Quinones. Transfer of Aromaticity from ipso-Benzene Ring to the Enol System(s)
}

\author{
Danuta Rusinska-Roszak \\ Institute of Chemical Technology and Engineering, Poznan University of Technology, ul. Berdychowo 4, \\ 60-965 Poznan, Poland; danuta.rusinska-roszak@put.poznan.pl \\ Academic Editor: Steve Scheiner \\ Received: 31 January 2017; Accepted: 15 March 2017; Published: 18 March 2017
}

\begin{abstract}
Intramolecular hydrogen bonding (HB) is one of the most studied noncovalent interactions of molecules. Many physical, spectral, and topological properties of compounds are under the influence of $\mathrm{HB}$, and there are many parameters used to notice and to describe these changes. Hitherto, no general method of measurement of the energy of intramolecular hydrogen bond $\left(\mathrm{E}_{\mathrm{HB}}\right)$ has been put into effect. We propose the molecular tailoring approach (MTA) for $\mathrm{E}_{\mathrm{HB}}$ calculation, modified to apply it to Ar-O-H $\cdots \mathrm{O}=\mathrm{C}$ systems. The method, based on quantum calculations, was checked earlier for hydroxycarbonyl-saturated compounds, and for structures with resonance-assisted hydrogen bonding (RAHB). For phenolic compounds, the accuracy, repeatability, and applicability of the method is now confirmed for nearly 140 structures. For each structure its aromaticity HOMA indices were calculated for the central (ipso) ring and for the quasiaromatic rings given by intramolecular $\mathrm{HB}$. The comparison of calculated HB energies and values of estimated aromaticity indices allowed us to observe, in some substituted phenols and quinones, the phenomenon of transfer of aromaticity from the ipso-ring to the H-bonded ring via the effect of electron delocalization.
\end{abstract}

Keywords: HOMA; intramolecular hydrogen bond; MTA; RAHB

\section{Introduction}

Noncovalent interactions, such as hydrogen bonding, play an important role in supramolecular chemistry, drug-receptor interactions, drug design in chemical and biological processes, including molecular recognition, and the bioactivity of macromolecules [1-3]. Hydrogen bonds (HBs) allow the definition of the crystal packing of many organic and organometallic structures, are the source of interesting properties of associated liquids, and can give valuable insights on the solubility of molecules. For almost one hundred years, different types of hydrogen bonding have been described, classified, measured, and compared, often providing an unquestionable explanation of numerous biological processes. Hydrogen bonds can be broadly classified as very strong, strong, medium, and weak, as cooperative and anti-cooperative, chelated and bifurcated, classic and unconventional, intermolecular and intramolecular, and resonance-assisted (RAHB) $[4,5]$ and charge-assisted ((+)CAHB and (-)CAHB) [6]. Classic types of $\mathrm{HB}$ occur between a hydrogen atom covalently bound with a strong electronegative atom (such as $\mathrm{O}, \mathrm{N}, \mathrm{Cl}$, or $\mathrm{F}$ ) and another electronegative atom, which plays the role of the hydrogen acceptor. In unconventional HBs, the C-H group [7-9] acts as a donor, while anions and $\pi$-electrons from unsaturated bonds or aromatic rings act as hydrogen acceptors $[6,10]$.

The strength of a hydrogen bonding can be modified by the presence of substituents, molecule configuration, and conformation possibilities, and induce different effects to electron delocalization in 
hydrogen-bonded systems. Geometrical, physical, topological, and spectral parameters are used [11-13] for the estimation of the strength of intermolecular bonding with good accuracy. When both the donor and the acceptor fragments belong to the same molecule, such estimations become more difficult.

The most commonly used method to estimate the energy of the intramolecular HBs is based on the cis-trans (or syn-anti) comparative analysis method [1,2,4,6]. For two conformers that essentially differ by the presence of one intramolecular $\mathrm{HB}$, a trans-conformer can be built by rotation of the hydrogen atom up to 180 degrees, with the optimization of such a prepared structure, or without. The energy of hydrogen bonding is estimated as the difference between the energies of both conformers.

The isodesmic reactions appear to provide more reasonable results than the cis-trans approach when used to evaluate the intramolecular interaction energy [14-16]. In isodesmic reactions [16] the number and types of bonds are conserved on the reactant and product sides of the reaction. The isodesmic method was used for the estimation of intramolecular HB energies based on the assumption that the total molecular energy can be partitioned into energies of chemically recognizable fragments $[17,18]$. This method is advocated for systems with one HB, but it is not recommended for the estimation of the single intramolecular H-bond energy in polyhydroxy systems [17].

The interatomic interactions, such as hydrogen bonds, can be described and classified by the electron density $\rho$ at the $(3,-1)$ bond critical points $(B C P)$ [19-22]. The ring critical points (RCP) found in the intramolecular $\mathrm{HB}$ region, also play a role in the estimation of interaction by reinforcing the binding for intermolecular bifurcated HBs [23] and for compounds with RAHB [24,25], even in two-ring (chelated intramolecular HB) systems. The electron density and other Atoms In Molecules (AIM) parameters at the RCP correlate with aromaticity indices and can be used for the estimation of the electron delocalization effect in aromatic and quasiaromatic ring systems $[10,26]$. Over the last two decades, the theoretical analysis of electron density topology (AIM theory) has been the most widely used method for the investigation of hydrogen bond systems by the electron density at the bond critical point $\rho_{\mathrm{BCP}}$, its Laplacian $\nabla^{2} \rho_{\mathrm{BCP}}$ value and the potential energy density $\mathrm{V}_{\mathrm{BCP}}$, which are occasionally treated as universal descriptors of the hydrogen bond strength $[10,27,28]$. The equation formulated by Espinosa [27] $E_{H B}=\frac{1}{2} V_{B C P}$ allows the calculation of the HB energy based on the potential energy density in its bond critical point $\left(\mathrm{V}_{\mathrm{BCP}}\right)$. Recently Afonin [28] introduced modifications to this equation using different linear regression coefficients in order to obtain a better correlation.

In 1994, Gadre [29] introduced the Molecular Tailoring Approach (MTA) method of ab initio quality computation of various electron properties of (large) supermolecules, which involves construction of the density matrix of the supermolecule from block matrices of smaller fragments, each representing a part of the supermolecule. This method was primarily drawn up for calculation of properties of silicious zeolite-clusters [29], and further for various biologically active systems as taxol, $\gamma$-cyclodextrin, $\alpha$-tocopherol, and other large organic or inorganic crystalline substances [29]. Next, Deshmukh [21] used this method for systems containing multiple $\mathrm{O}-\mathrm{H} \cdots \mathrm{OH}$ intramolecular hydrogen bonds. Their energy was calculated by the fragmentation approach: the original optimized molecule was cut into three overlapping fragments, which are obtained by replacing the $\mathrm{OH}$ groups with the hydrogen atom, without optimization, to avoid conformational changes in it. It was shown that MTA yields more reliable $\mathrm{H}$-bond energy values than the isodesmic method, and can be easily applied to any complicated polyhydroxy H-bonded systems.

In the study carried out by Deshmukh et al. [17], it was demonstrated that the estimated MTA values are consistent with the corresponding $\mathrm{H}$-bond lengths, but the isodesmic/homodesmic reaction approach is not a good enough method for the estimation of H-bond energy for multiple H-bonded intramolecular systems. In contrast, the molecular tailoring approach yields more reliable H-bond energy values and can be easily applied to any complicated $\mathrm{H}$-bonded systems with large numbers of $\mathrm{OH} \cdots \mathrm{OH}$ interactions. This offers several interesting possibilities for exploring intramolecular interactions in large biomolecules. The typical error involved in the calculation of is quite small ( 0.5 kcal/mol for polyalcohols) [21]. 
The method was developed by us for saturated hydroxycarbonyl compounds with six-, seven-, and eight-membered ring of intramolecular hydrogen bonds [30], and for many structures with various types of RAHB [25]. In case of the first group of compounds, the examination of 140 examples confirmed that the method gives reproducible results, precise and congruent with some of the aforementioned parameters, such as the length of $\mathrm{HB}$, length of the $\mathrm{O}-\mathrm{H}$ covalent bond, distance of the $\mathrm{O} \cdots \mathrm{O}$, IR frequency of the $\mathrm{O}-\mathrm{H}$ group, chemical shift of the H-bonded proton, electron density, and its Laplacian $\left(\nabla^{2} \rho_{\mathrm{BCP}}\right)$ at the bond critical point. In case of the second group (RAHB), the fair agreement of calculated dependences was observed for the length and angle of the $\mathrm{HB}$, covalent $\mathrm{O}-\mathrm{H}$ bond and the $\mathrm{O} \cdots \mathrm{O}$ distance, $\mathrm{O}-\mathrm{H}$ frequency, and the electron density in the critical bond and ring critical bond. The HB angle, $\delta_{\mathrm{H}}$ and $\nabla^{2} \rho_{\mathrm{BCP}}$ of intramolecular resonance-assisted hydrogen bond values were not useful for estimating of HB strength. Peculiar exceptions may be observed even in the case of good relationships, which exclude the use of the aforementioned parameters, but are explicable from a structural point of view.

In our previous reports [25,30] the aromatic hydroxycompounds, i.e., phenols were not interpreted, because it was found that they represent a different type of intramolecular hydrogen bond. Aromaticity is a collective phenomenon of $\pi$-conjugation, sensitive to different external effects, which also exerts mutual influence. Such structures have the same phenolic group as a hydrogen bond donor, and constitute a considerable part of naturally-occurring substances, which are important in biochemical processes, as well as in medicinal and pharmaceutical applications. For example some flavonoids exhibit anticancer, anti-inflammatory, and anti-oxidant properties, acting as free radical scavengers, due to the dissociation of the $\mathrm{OH}$ bond [31]. Therefore, it is important to recognize the role played by the HB in stabilizing radicals and the anionic species in phenols, for example, in acylphloroglucinols [32,33]. Usinic acid [34] produced by lichens acts as an effective antibiotic and scytalone dehydratase is crucial for the fungal melanin biosynthetic pathway [35]. Some quinones (lapachol, caryopteron) [36] exhibit important cytotoxic activity against cancer cells, naphthazarin [37] acts as an antibacterial agent, apoptosis inducer, antineoplastic agent, and the most common application of anthraquinones remains the dyeing of both natural and synthetic fibres [38].

The strength of the hydrogen bond in saturated hydroxycompounds was estimated at $1.4-7 \mathrm{kcal} / \mathrm{mol}$, additional unsaturated, but not conjugated, elements increased it to $13.7 \mathrm{kcal} / \mathrm{mol}$ [30] while, in the case of structures with RAHB, the energy of the hydrogen bond $\left(\mathrm{E}_{\mathrm{HB}}\right)$ was calculated in the range of 8.2 to $23.6 \mathrm{kcal} / \mathrm{mol}$ [25] with $14.5 \mathrm{kcal} / \mathrm{mol}$ for the representative enol of malonaldehyde. Due to the additional external four- and five-membered stiffening rings, this value may be weakened and is sensitive to the changes resulting from various substitution.

In this study, mono- , di-, and triphenols substituted at the ortho- position by various functional groups containing carbonyl, and additionally substituted by different groups donating or withdrawing electrons (Table 1), were examined. The study includes hydroxyquinones and anthraquinones, as they exhibit the same relationships between energy and other characteristics of the hydrogen bonding (Tables 2 and 3). Some natural or more complicated structures, in which the phenolic group is engaged in intramolecular HB with the carbonyl group, were described separately. The structures with the phenolic group involved in seven- or eight-membered HB ring, which are characterized by low $\mathrm{E}_{\mathrm{HB}}$, do not comply with structural conditions and are presented in the Supplementary Materials. The term energy of hydrogen bonding $\left(\mathrm{E}_{\mathrm{HB}}\right)$ has been used throughout the article to express the difference between energies of two molecules: one which is stabilized by hydrogen bonding, and another in which "the internal HB is broken without causing other structural or electronic changes" [11].

Note that substituted, condensed polycyclic hydrocarbon systems which contain hydrogen bonded molecules are excluded from this work, due to their dependence on the position of $-\mathrm{OH}$ and $-\mathrm{C}=\mathrm{O}$ substitution $[39,40]$. 


\section{Computational Methods}

For estimating the $\mathrm{O}-\mathrm{H} \cdots \mathrm{O}=\mathrm{C}$ intramolecular hydrogen bond energy, a systematic fragmentation of each optimized molecule was carried out, using modified Deshmukh's [21] methodology, which consists of comparing the energies of the fragments of a molecule, in which the atoms of the donor, acceptor, and both groups forming the hydrogen bond are successively removed. This allowed avoiding contact between both groups in any such built structures.

Each functional group participating in intramolecular hydrogen bonding was replaced by an inserted hydrogen atom, as in [25,30]: the valences of the cut regions (atoms) were satisfied by the addition of the hydrogen atoms at appropriate directions and arbitrary constraint distances equal to $1.1 \AA$ [21]. It is very important that the hydrogen atom replaces only single but not multiple bonds, and that after this operation the distance between both added hydrogen atoms is greater than $2.2 \AA$ (double the van der Waals radius) to avoid steric hindrance. We propose the fragmentation of the hydrogen-bonded structure in such a manner that the $\mathrm{C}=\mathrm{O}$ group is removed with the part of the molecule "behind" $\mathrm{C}_{\alpha}, \mathrm{C}_{\beta}$, or $\mathrm{C}_{\gamma}$ at the site opposite to the $\mathrm{OH}$ group (examples are presented in Supplementary Materials, Figure S1). The energies of such parts (Scheme 1) were calculated without optimization at the MP2(full)/6-311++G(2d,2p) level and used to calculate the strengths of hydrogen bonds according the Equation (1) given in Scheme 1.

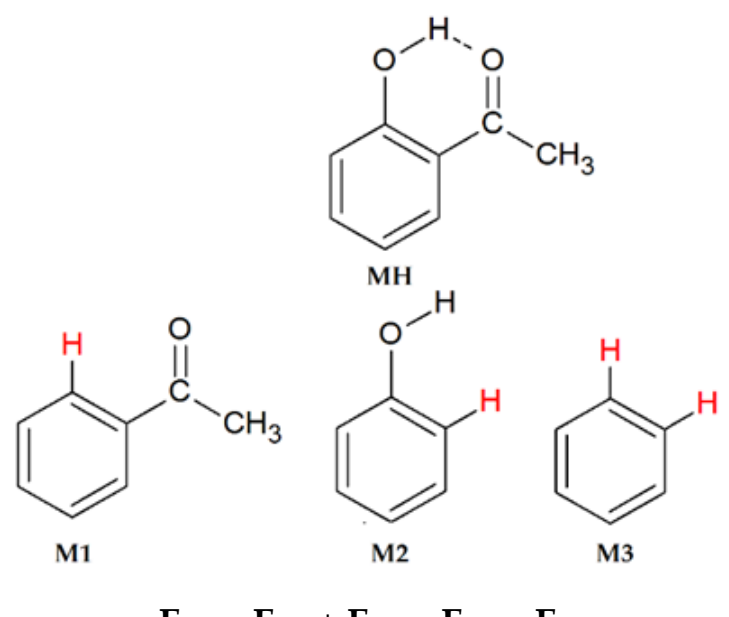

$$
\mathrm{E}_{\mathrm{HB}}=\mathrm{EM}_{\mathrm{M}}+\mathrm{EM}_{\mathrm{M}}-\mathrm{EM}_{3}-\mathrm{E}_{\mathrm{MH}}
$$

Scheme 1. General principles of molecular tailoring approach (MTA) fragmentation.

All candidate structures were first optimized by the B3LYP density function [41,42] of the B3LYP/6-311++G(d,p) basis set [21] using the Gaussian 09 [43] program package, as described previously [25,30], due to the fact that this method provided credible results in the past [44] when dealing with $\mathrm{H}$-bonded systems. In the next step the structures were checked by the vibrational analysis at this level and were found to represent the true energy minima. The calculated $v_{\mathrm{OH}}$ and $v_{\mathrm{C}=\mathrm{O}}$ frequencies were identified with the GaussView 5.0.9 package, without correction for the zero-point energies. At the same level, the absolute proton shielding for each structure and TMS (tetramethylsilane standard) were obtained using the gauge-including atomic orbital (GIAO) method [45]. The SCF GIAO magnetic isotropic shielding tensors of $\mathrm{H}$-bonded hydrogen atoms were used to calculate the chemical shifts $\left(\delta_{\mathrm{H}}\right)$. Afterwards, the electron correlation was included via the Møller-Plesset treatment of the second order (MP2), in which each structure was finally optimized with MP2(FC)/6-311++G(2d,2p) and its energy was specified with $\mathrm{MP} 2(\mathrm{full}) / 6-311++\mathrm{G}(2 \mathrm{~d}, 2 \mathrm{p})$ calculations. The topological properties of the electron density at the bond critical points (BCPs) were characterized using the Bader Atoms In Molecules methodology (AIM) with the AIM2000 [46] and AIMAll [47] program packages for every fully-optimized geometry. The AIM analyses of the wavefunction have been conducted on true MP2 wavefunctions (using "natural orbitals" of the MP2 first-order total density matrix). Similarly to a 
previous report $[25,30]$, the electron density $\rho_{\mathrm{BCP}}$ at the $(3,-1)$ bond critical point, its Laplacian $\nabla^{2} \rho_{\mathrm{BCP}}$ (for the $\mathrm{BCP}$ between the hydrogen atom of the $\mathrm{OH}$ donor group, and the oxygen atom of the $\mathrm{O}=\mathrm{C}$ acceptor group), potential energy density $\mathrm{V}_{\mathrm{BCP}}$, and the electron density $\rho_{\mathrm{RCP}}$ (at the ring critical point in the centre of the newly-formed six-membered ring, which includes the hydrogen bonded atoms, further named as the "HB-ring") were selected to describe the nature of the hydrogen bonding.

Aside from the above-mentioned parameters used to describe the electron distribution in the intramolecular hydrogen bonds, additional geometry-dependent indices of the aromaticity proved useful in the case of substituted phenols. The extra ring formed by substituents interacting through the hydrogen bond in phenols affect the strength of the HB and the local aromaticity of the aromatic ring $[48,49]$. The phenolic ring, named ipso-ring, can be described by the Harmonic Oscillator Model of Aromatic stabilization (HOMA) index [12,50-52] defined by Krygowski's equation (Equation (2)):

$$
\mathrm{HOMA}=1-\frac{\alpha}{\mathrm{n}} \sum\left(\mathrm{R}_{o p t}-R_{i}\right)^{2}
$$

where the number of bonds taken into the summation $n=6 ; \alpha=257.7, R_{\text {opt }}=1.388 \AA$. and $R_{i}$ stands for the running bond length.

The interaction between the ring and the hydrogen bond is regarded to and named as quasi-aromatic, and can be described by the quasiHOMA index, which was calculated by Equation (2), where the number of all bonds taken into the summation $\mathrm{n}=4$, i.e., for $\mathrm{C}-\mathrm{O}$ and $\mathrm{C}=\mathrm{O}$ bonds $\alpha=157.38$, $\mathrm{R}_{\text {opt }}=1.265$, and for C-C bonds $\alpha=257.7, \mathrm{R}_{\mathrm{opt}}=1.388 \AA$, and $\mathrm{R}_{\mathrm{i}}$ stands for $\mathrm{C}-\mathrm{O}, \mathrm{C}=\mathrm{O}, \mathrm{C}-\mathrm{C}$, and $\mathrm{C}_{\mathrm{ar}}-\mathrm{C}_{\mathrm{ar}}$ bond lengths.

The strength of the $\mathrm{HB}$ and its relation with the $\pi$-electron delocalization within the ipso-ring is discussed, and analysis of the aromaticity of the quasi-ring is performed in relation to the strength of the intramolecular HB that is formed.

\section{Results}

The geometry of each intramolecular hydrogen bond for 140 fully-optimized structures was described using four geometrical parameters: length of the $\mathrm{O}-\mathrm{H}$ covalent bond $\left(\mathrm{d}_{\mathrm{OH}}\right)$, the distance of the $\mathrm{HB}$ as $\mathrm{H} \cdots \mathrm{O}\left(\mathrm{r}_{\mathrm{HB}}\right)$, the distance between both the proton donor and proton acceptor oxygen atoms as $\mathrm{O} \cdots \mathrm{O}\left(\mathrm{d}_{\mathrm{O}} \cdots \mathrm{O}\right)$, and the angle of the $\mathrm{HB}$ as $\mathrm{O}-\mathrm{H} \cdots \mathrm{O}\left(\phi_{\mathrm{HB}}\right)$. The complementary data, including the calculated frequency of $\mathrm{O}-\mathrm{H}$ and $\mathrm{C}=\mathrm{O}$ stretching, the hydrogen chemical shift, and HOMA indices, including the AIM characteristics of the analysed structures, are collected in Table S1 (Supplementary Materials). Only the diagrams which show significant correlations between the listed parameters and the calculated $\mathrm{E}_{\mathrm{HB}}$ are included at the end of this study (vide infra Figure 6A-J).

Table 1 contains the structural parameters of stable conformers of phenolic intramolecular hydrogen bonding for unsubstituted $o$-hydroxycarbonyl compounds, substituted $o$-hydroxyaldehydes, and substituted $o$-hydroxyketones and acids. The last column contains data regarding the related strength of $\mathrm{HB}$ cited in the literature. Note that the $\mathrm{E}_{\mathrm{HB}}$ are given as positive values. 
Table 1. Harmonic Oscillator Model of Aromatic stabilization (HOMA) and quasiHOMA indices and energy of the hydrogen bond $(\mathrm{kcal} / \mathrm{mol})$, calculated for unsubstituted ortho-hydroxycarbonyl compounds, substituted ortho-hydroxyaldehydes, substituted hydroxyketones and acids.

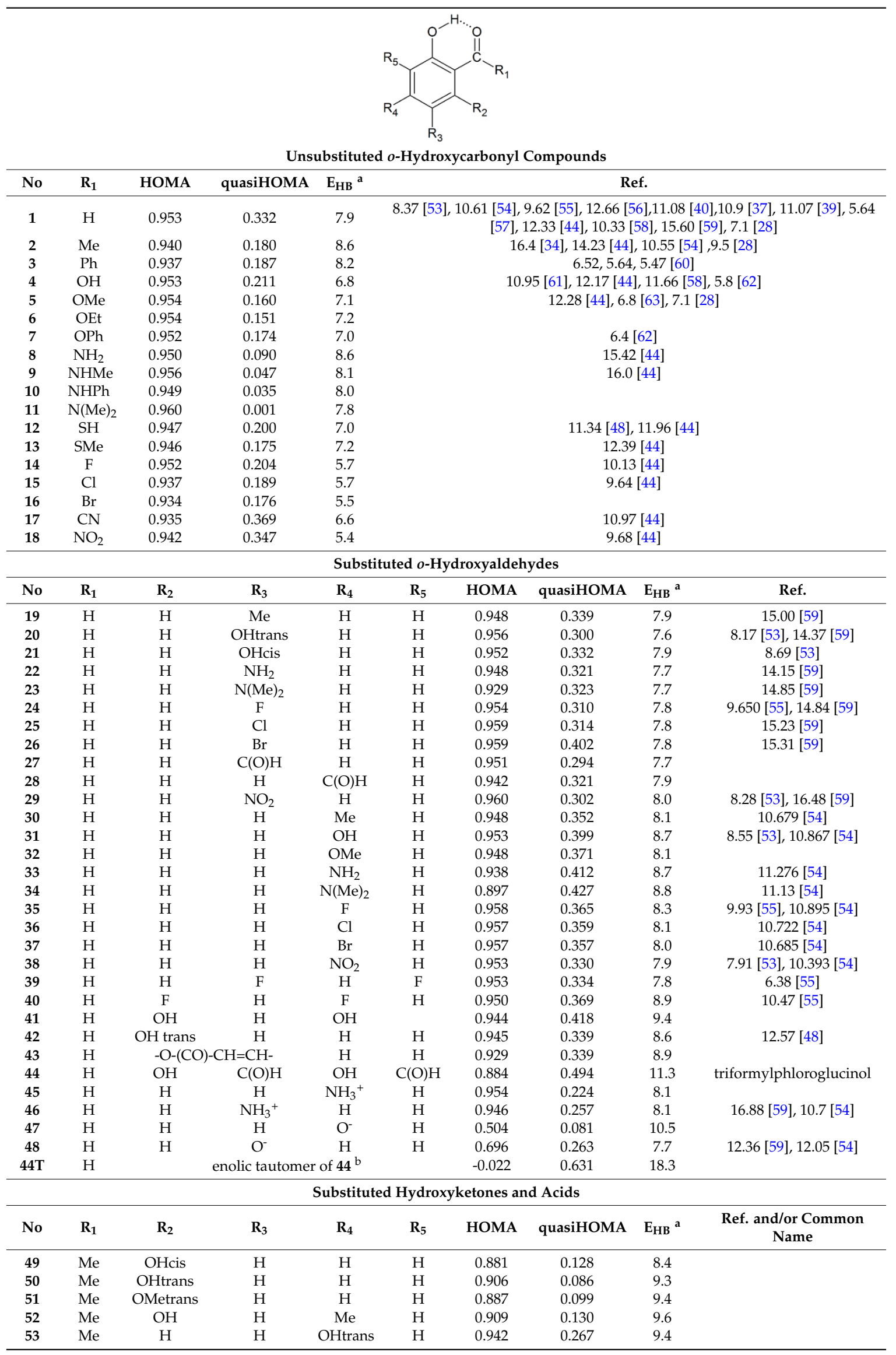


Table 1. Cont.

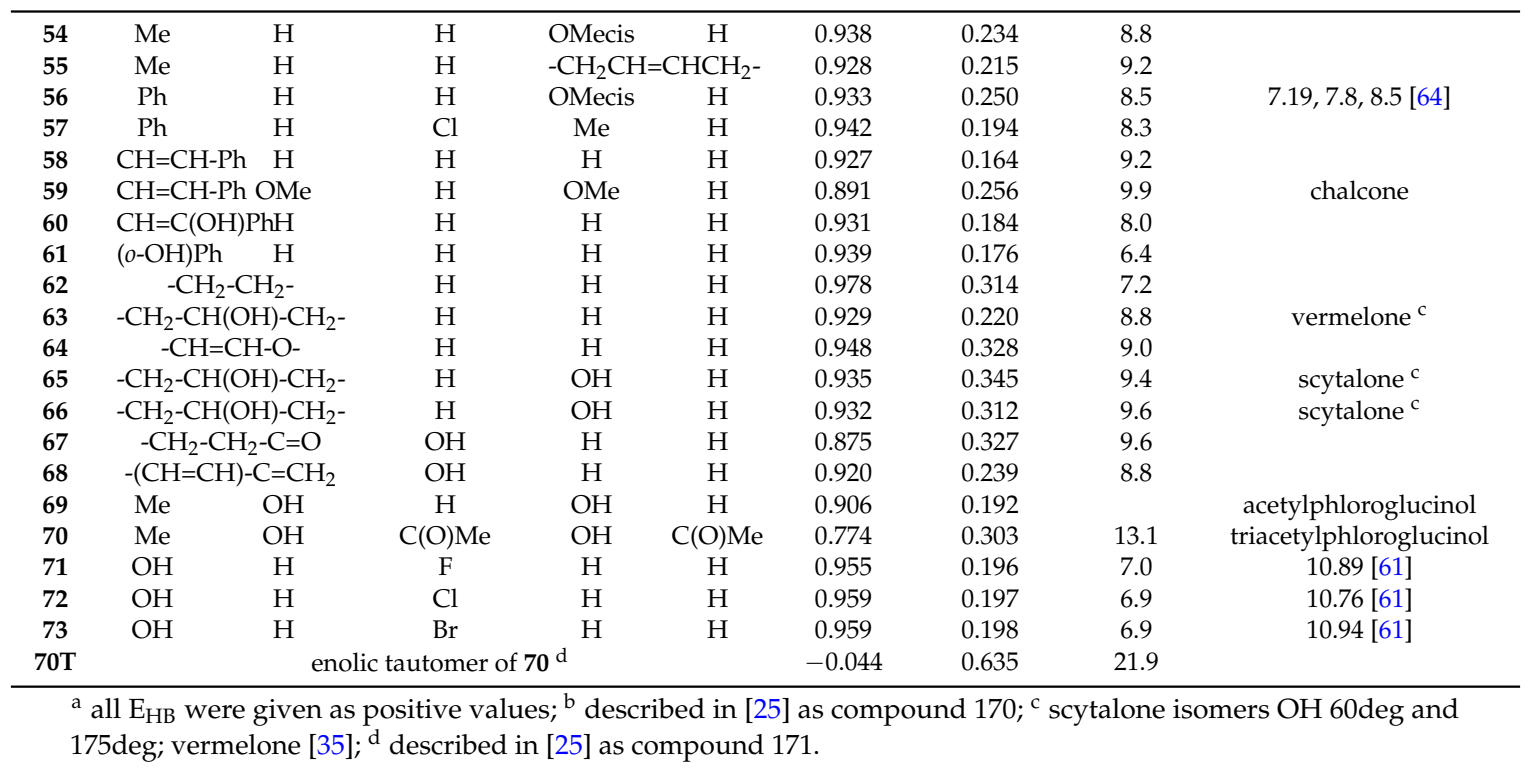

The last column of Table 1 presents literature $\mathrm{E}_{\mathrm{HB}}$ values calculated by different methods which are generally inconsistent. The values obtained with the close-open method $[44,54,59]$ seem to be overestimated, even up to two-times, whereas the values obtained with the homodesmic [53], as well as the potential energy density, methods [28] are similar to those presented in this study.

In the first part of Table 1, aside from salicylaldehyde $\mathbf{1}$, acetophenone $\mathbf{2}$, benzophenone $\mathbf{3}$, and salicylic acid 4, a number of acid derivatives are presented: esters, amides, sulphides, or halides.

The vast majority of intramolecular HB energy values calculated for phenols listed in Table 1 range from 5.4 to $10 \mathrm{kcal} / \mathrm{mol}$. The weakest HBs are observed in the case of acid halides 14, 15, and 16, whereas the strongest HBs occur in tri-substituted structures 44 and $\mathbf{7 0}$, as well as anions $\mathbf{4 7}$ and 48, in which the decreased HOMA value indicates a loss of aromaticity in the ipso ring. The quasiHOMA index values are more diverse: from approximately zero to 0.427 , or even 0.494 in the case of structure 44, and confirm the high influence of electron donor properties, as well as the position of substitution. The notable decrease of aromaticity in the quasiaromatic ring (HB-ring) is caused by substituents, which may conjugate with the carbonyl group (8-11).

The explanation is shown in Figure 1, in which energetic and geometric parameters of salicylaldehyde 1 are compared with $N, N$-dimethylsalicylamide 11 . The elongation of $C=O, C_{a r}-C(=O)$ and $\mathrm{C}-\mathrm{O}$ bonds is a result of participation of free electrons of amide nitrogen atoms in carbonyl resonance. Comparison of the obtained values of bond length, C-N-C angle, and Wiberg bond order [65] for the C-N bond in trimethylamine $(1.458 \AA, 110.1,0.996)$ and trimethylimine $(1.281 \AA$, $118.8,1.862)$ (optimized as each of the analysed compounds) with these values obtained for structure $11(1.359 \AA, 117.5,1.173)$ confirms the proposed resonance structure which includes the sp ${ }^{2}$ hybridized nitrogen atom.

Interestingly, when the - $\mathrm{CN}$ (structure 17) or - $\mathrm{NO}_{2}$ (structure 18) groups (the only substituents without a conjugated lone electron pair) are linked as the $\mathrm{R}_{1}$ group, the hydrogen bond is weaker and quasiHOMA is approximately as high as in salicylaldehyde $\mathbf{1}$ (Table 1).

In the group of substituted salicylaldehydes, the energies of HB are approximately at the same range $(7.5-8.9 \mathrm{kcal} / \mathrm{mol})$, with a few exceptions (2,4,6-trihydroxybenzaldehyde $41-9.4 \mathrm{kcal} / \mathrm{mol}$; the mono anionic form of 2,4-dihydroxybenzaldehyde 47-10.5 kcal/mol; triformylphloroglucinol $44-11.3 \mathrm{kcal} / \mathrm{mol})$. The quasiHOMA index for most compounds in this group (0.29-0.42) resembles the value of the model compound 1. Note that the presence of the oxido (phenolic anion) group in the $\mathrm{R}_{4}$ position (para- to the carbonyl) in the anionic structure 47 causes almost total dearomatisation of 
the HB-ring, and a strong decrease of the HOMA index of the ipso-ring (to ca. 0.5). This may be caused by the resonance of extra electrons, which impairs aromaticity and creates the $(-)$ CAHB character of HB. This explanation is evident in Figure 1, in which the stronger $\mathrm{HB}$ arises with the elongation of $\mathrm{C}-\mathrm{O}$, as well as $\mathrm{C}=\mathrm{O}$ and shortening of $\mathrm{C}_{\mathrm{ar}}-\mathrm{C}$ bonds (relative to salicylaldehyde reference $\mathbf{1}$ ).

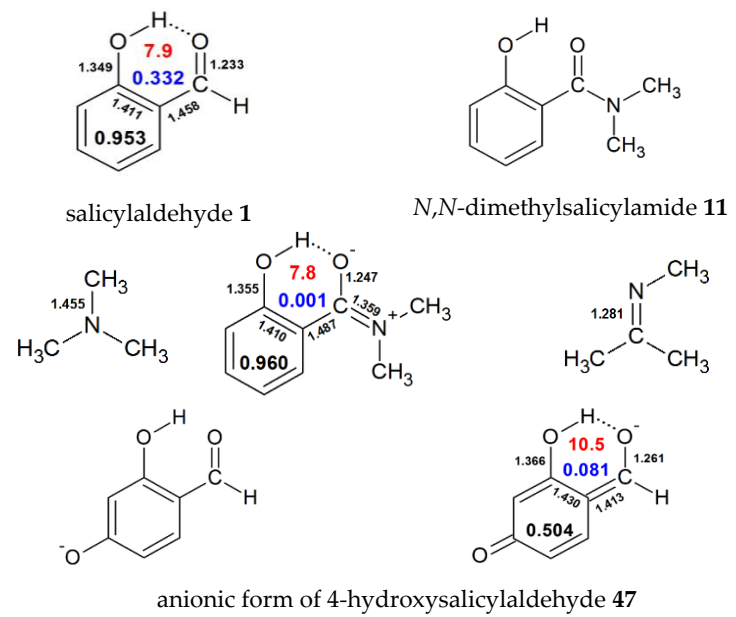

Figure 1. The $\mathrm{E}_{\mathrm{HB}}$ (in red) and selected geometric parameters of salicylaldehyde 1, $N, N$-dimethylsalicylamide 11 and 2-hydroxy-4-hydrylidylbenzaldehyde $\mathbf{4 7}$ as well as their essential resonance structures; HOMA and quasiHOMA (in blue) values were given in relevant rings.

In the substituted hydroxyketones group in Table 1, the strength of $\mathrm{HB}$ in the case of hydroxyketones is higher (average $\mathrm{E}_{\mathrm{HB}}=8.57 \mathrm{kcal} / \mathrm{mol}$ ) compared to related aldehydes. The halogen substitution at the $R_{3}$ position of salicyl acid 4 has no influence on the energy of intramolecular HB in structures $\mathbf{7 1}$, 72 , and 73 [61].

In the case of triformylphloroglucinol 44 a remarkable reduction of the aromaticity of ipso-ring may be observed, which is also likely in its corresponding triacetyl derivative 70. The tautomeric forms of both compounds $44 \mathrm{~T}$ and $70 \mathrm{~T}$ were presented in a previous study [25] concerning RAHB. The tautomers 44T and 70T arise from ketoforms through the displacement of three protons with the allied changes in geometry and rearrangement of $\pi$-electrons in the system-from the ipso-ring to the outside. The results are shown in Figure 2.

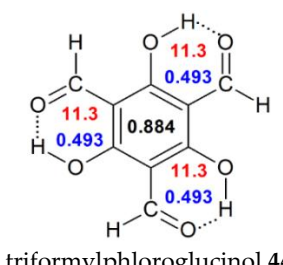

loroglucinol 44

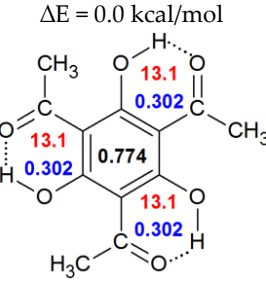

triacetylphloroglucinol 70

$\Delta \mathrm{E}=0.0 \mathrm{kcal} / \mathrm{mol}$

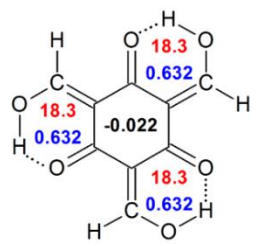

2,4,6-tri(hydroxymethylidene)cyclohexa-1,3,5-trione $44 \mathrm{~T}$ (170 in [15]) $\Delta \mathrm{E}=10.4 \mathrm{kcal} / \mathrm{mol}$

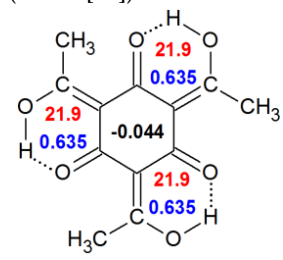

2,4,6-tri(1-hydroxyethylidene)cyclohexa-1,3,5-trione $70 \mathrm{~T}$ (171 in [25]) $\Delta \mathrm{E}=7.8 \mathrm{kcal} / \mathrm{mol}$

Figure 2. The transfer of aromaticity in triformyloglucinol 44 and triacetylphloroglucinol 70 from the ipso-ring to the enolic system. Values of quasiHOMA (in blue) and $\mathrm{E}_{\mathrm{HB}}$ (in red) were given in the centre of the HB-ring, whereas the HOMA value was given in the ipso-ring. 
The structures of formyl- and acetyl- phloroglucinols $\mathbf{4 4}$ and $\mathbf{7 0}$ are much more stable compared to their enolic analogues $44 \mathrm{~T}$ and $70 \mathrm{~T}$, with the difference of $\Delta \mathrm{E}$ values at 10.4 and $7.8 \mathrm{kcal} / \mathrm{mol}$, respectively. In less stable RAHB structures, the HOMA indices of ipso-rings fall to near zero values, and the quasiHOMA indices of the rings involved with HBs increase almost twice, with a significant increase of the HB's strength. These enolic structures resembles the triphenylene, in Clar's aromatic $\pi$-sextet rule for polycyclic aromatic hydrocarbons (PAHs), considered as more stable and more aromatic than the other rings in benzenoid species. Therefore, the internal ipso-ring is often named an "empty" ring having six $\pi$-electrons $[66,67]$ and the observed changes are named as transfer of aromaticity.

Table 2 contains results obtained for hydroxynaphthoquinones. Similarly, Table 3 reports hydrogen bonding in selected hydroxyanthraquinones; however, a number of more complex structures of biological importance are presented separately in Table 4. Some of the calculated energies of HB were compared with the previously published values [34,37,58,68-72].

Table 2. HOMA and quasiHOMA indices and energy of hydrogen bond (kcal/mol) calculated for hydrogen bonding (HB) ring in substituted hydroxynaphthoquinones structures; common names of some natural products and the cited energetic data were given in the last column.

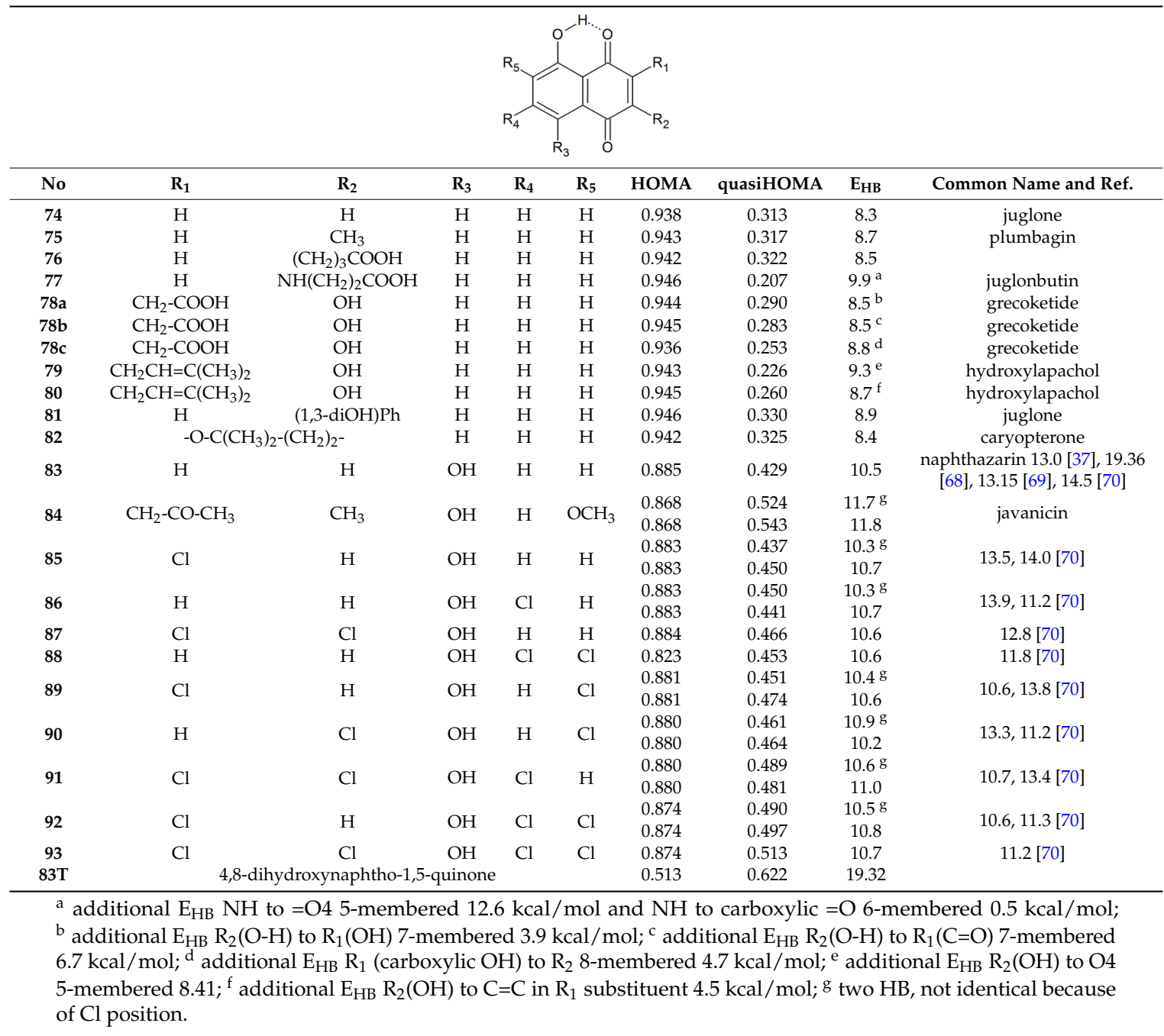

In terms of energy, the hydroxynaphthoquinones are similar to monohydroxyketones 2 or 3 ( $\mathrm{E}_{\mathrm{HB}}$ of approximately $8.5 \mathrm{kcal} / \mathrm{mol}$ ), as well as for HOMA indices, even with additional hydroxyl-, aryl-, or alkyl- substituent. In the case of naphtazarin $\mathbf{8 3}$, a dihydroxynaphtoquinone, and the remaining quinones stabilized by two intramolecular $\mathrm{HB}$, their $\mathrm{E}_{\mathrm{HB}}$ increased beyond $10 \mathrm{kcal} / \mathrm{mol}$, because of the effect of extra $\mathrm{OH}$ substitution, with free electrons, which participate in the whole aromatic system. 
The substitution by one, two, three, or four chlorine atoms revealed the sensitivity of the applied MTA method of calculation to asymmetrical substitution. However, the differences among $E_{\mathrm{HB}}$ values associated with the position of substitution and number of $\mathrm{Cl}$ substituents are low.

For the discussed 5,8-dihydroxynaphtho-1,4-quinone 83 and for its tautomeric 4,8-dihydroxynaphtho1,5-quinone 83T (Figure 3), a difference between energies of the intramolecular HB (shown in Table S1) of $10.5 \mathrm{kcal} / \mathrm{mol}$ and $19.3 \mathrm{kcal} / \mathrm{mol}$, respectively, is observed; however, the last value is distinctive for RAHB systems. Moreover, the quasiHOMA and HOMA indices (0.429 and 0.885, respectively) indicate that while 83 belongs to typical aromatic structures, its tautomer 83T (with quasiHOMA and HOMA indices at 0.622 and 0.513 , respectively), is a particular combination of the two related RAHB couplings. The condensed rings in the tautomer 83T have no aromatic character and their HOMA indices are uncommonly low. Moreover, on the basis of quasiHOMA values and other hydrogen bonding indicators, e.g., $\mathrm{OH} \cdots \mathrm{O}$, and $\mathrm{O} \cdots \mathrm{O}$ distances, $\mathrm{O}-\mathrm{H}$ bond length, spectral and topological properties (see Table S1 and Figures S4-S7), the resonance spacers confirm the non-aromatic character of hydrogen bonding.

It can be suggested that the naphthazarine case, and its enol, are the next example of the transfer of aromaticity from the ipso-ring to the external enolic system.

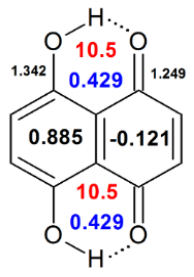

5,8-dihydroxynaphtho-1,4-quinone 83 $\Delta \mathrm{E}=0.0 \mathrm{kcal} / \mathrm{mol}$

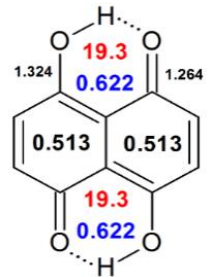

4,8-dihydroxynaphtho-1,5-quinone 83T $\Delta \mathrm{E}=6.4 \mathrm{kcal} / \mathrm{mol}$

Figure 3. The transfer of aromaticity from ipso-ring to the enolic system in naphthazarin. Values of quasiHOMA (in blue) and $\mathrm{E}_{\mathrm{HB}}$ (in red) were given in the centre of the hydrogen bonded ring, whereas the HOMA value was given in the ipso-ring.

Table 3. HOMA and quasiHOMA indices and energy of hydrogen bond (kcal/mol) calculated for HB rings in substituted hydroxyanthraquinones.

\begin{tabular}{|c|c|c|c|c|c|c|c|c|c|c|}
\hline No & $R_{1}$ & $\mathbf{R}_{2}$ & $\mathbf{R}_{3}$ & $\mathbf{R}_{4}$ & $\mathbf{R}_{5}$ & $\mathbf{R}_{6}$ & $\mathbf{R}_{7}$ & HOMA & quasiHOMA & $\mathrm{E}_{\mathrm{HB}}$ \\
\hline 94 & $\mathrm{H}$ & $\mathrm{H}$ & $\mathrm{H}$ & $\mathrm{H}$ & $\mathrm{H}$ & $\mathrm{H}$ & $\mathrm{H}$ & 0.929 & 0.301 & $8.8^{\mathrm{a}}$ \\
\hline 95 & $\mathrm{H}$ & $\mathrm{H}$ & $\mathrm{H}$ & $\mathrm{H}$ & $\mathrm{H}$ & $\mathrm{H}$ & $\mathrm{OH}$ & 0.939 & 0.310 & 10.0 \\
\hline 96 & $\mathrm{H}$ & $\mathrm{H}$ & $\mathrm{H}$ & $\mathrm{OH}$ & $\mathrm{H}$ & $\mathrm{H}$ & $\mathrm{H}$ & 0.933 & 0.316 & $9.1^{b}$ \\
\hline 97 & $\mathrm{H}$ & $\mathrm{H}$ & $\mathrm{H}$ & $\mathrm{H}$ & $\mathrm{OH}$ & $\mathrm{H}$ & $\mathrm{H}$ & 0.872 & 0.404 & $10.5^{\mathrm{c}}$ \\
\hline 98 & $\mathrm{OH}$ & $\mathrm{H}$ & $\mathrm{H}$ & $\mathrm{H}$ & $\mathrm{H}$ & $\mathrm{H}$ & $\mathrm{H}$ & 0.927 & 0.344 & 7.6 \\
\hline 99 & $\mathrm{OH}$ & $\mathrm{H}$ & $\mathrm{H}$ & $\mathrm{OH}$ & $\mathrm{OH}$ & $\mathrm{H}$ & $\mathrm{H}$ & $\begin{array}{l}0.870 \\
0.740\end{array}$ & $\begin{array}{l}0.448 \\
0.366\end{array}$ & $\begin{array}{c}9.9 \\
9.3^{\mathrm{d}}\end{array}$ \\
\hline 100 & $\mathrm{OH}$ & $\mathrm{OH}$ & $\mathrm{H}$ & $\mathrm{H}$ & $\mathrm{OH}$ & $\mathrm{H}$ & $\mathrm{H}$ & $\begin{array}{l}0.870 \\
0.870\end{array}$ & $\begin{array}{l}0.458 \\
0.388\end{array}$ & $\begin{array}{c}9.5^{\mathrm{d}} \\
11.5^{\mathrm{d}}\end{array}$ \\
\hline 101 & $\mathrm{H}$ & $\mathrm{OH}$ & $\mathrm{COOH}$ & $\mathrm{CH}_{3}$ & $\mathrm{OH}$ & $\mathrm{H}$ & $\mathrm{OH}$ & $\begin{array}{l}0.871 \\
0.871 \\
0.881\end{array}$ & $\begin{array}{l}0.518 \\
0.448 \\
0.024\end{array}$ & $\begin{array}{c}11.6^{\mathrm{e}} \\
10.9^{\mathrm{e}} \\
5.6^{\mathrm{e}}\end{array}$ \\
\hline $97 \mathrm{~T}$ & $\mathrm{H}$ & $\mathrm{H}$ & $\mathrm{H}$ & $\mathrm{H}$ & $\mathrm{R}_{5}=\mathrm{O}, \mathrm{R}_{10}=\mathrm{OH}$ & $\mathrm{H}$ & $\mathrm{H}$ & $\begin{array}{l}0.420 \\
0.132\end{array}$ & $\begin{array}{l}0.561 \\
0.671\end{array}$ & $\begin{array}{l}14.9 \\
22.1\end{array}$ \\
\hline
\end{tabular}

${ }^{\mathrm{a}} \mathrm{E}_{\mathrm{HB}}=13.36 \mathrm{kcal} / \mathrm{mol}$ in [58]; ${ }^{\mathrm{b}}$ anthrarufin; ${ }^{\mathrm{c}}$ quinizarin; ${ }^{\mathrm{d}}$ quinalizarin; three HB: two chelated to O9 and one to $\mathrm{O} 10$, add. 5-membered ring $\mathrm{R}_{2}(\mathrm{O}-\mathrm{H})$ to $\mathrm{R}_{1}(\mathrm{O}-\mathrm{H}) 2.6 \mathrm{kcal} / \mathrm{mol}$ in cooperation; ${ }^{\mathrm{e}}$ carmin acid without glicoside; two $\mathrm{HB}$ to $\mathrm{O} 9$ and $\mathrm{O} 10$; add. $\mathrm{R}_{2}(\mathrm{O}-\mathrm{H})$ to $\mathrm{R}_{3}(\mathrm{C}=\mathrm{O}) 6$-membered ring $5.6 \mathrm{kcal} / \mathrm{mol}$. 
The hydroxyanthraquinones, known and widely applied as natural pigments and synthetic dyes, are characterized by strong intramolecular hydrogen bonds and values of HOMA indices, which resemble those of quinones (Table 3). Comparison of anthrarufin 96 and quinizarin 97 (Figure 4) indicated that the growth of the quasiHOMA index is accompanied by the decrease of the HOMA for the ipso-rings, and that each substituted hydroxyl group increases the strength of intramolecular hydrogen bonding.
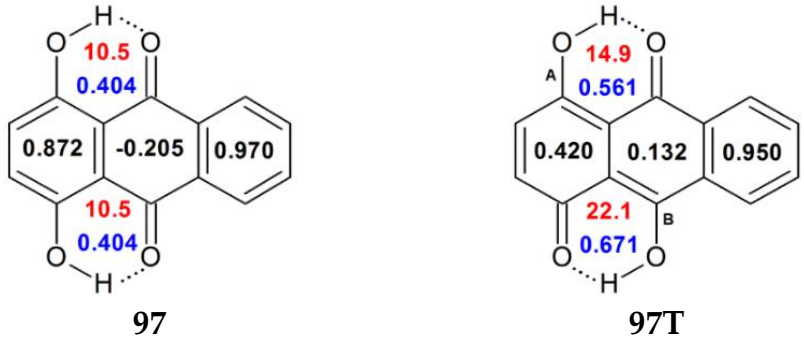

Figure 4. The transfer of aromaticity from ipso-ring to the enolic system. Values of quasiHOMA (in blue) and $\mathrm{E}_{\mathrm{HB}}$ (in red) were given in the centre of the hydrogen bonded ring, whereas the HOMA value was given in the ipso-ring.

Comparison of energies $\mathrm{E}_{\mathrm{HB}}$, quasiHOMA and $\mathrm{HOMA}$ indices of the tautomer of dihydroxyanthraquinone $97 \mathrm{~T}$ with those obtained for the tautomer of dihydroxyquinone 83T, allowed the observation of the same effect of the transfer of aromaticity from two ipso-rings. For 97T HOMA values were reduced to 0.420 and 0.132 (for A and B systems, respectively, to H-bonded rings), due to $\pi$-electrons delocalization (quasiHOMA values increased to as much as 0.561 and 0.671 compared to 0.404 in 99 and 0.332 for model salicylaldehyde 1). The external unsubstituted aromatic ring, not involved in hydrogen bonding, essentially retains its HOMA value.

Table 4. Energy of hydrogen bond $(\mathrm{kcal} / \mathrm{mol})$ as well as HOMA and quasiHOMA indices calculated for $\mathrm{HB}$ rings for some biological active phenols.

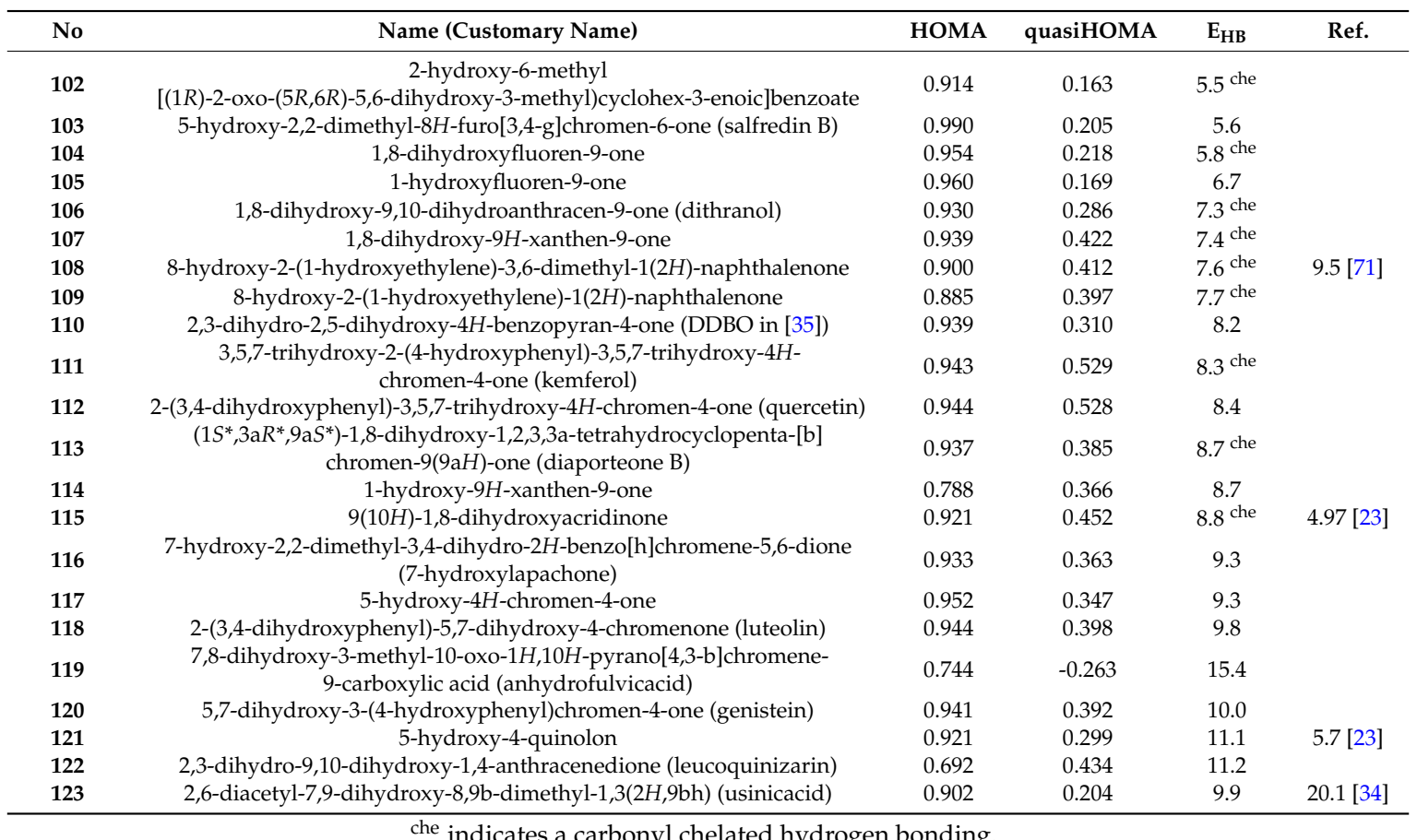


Many of the analysed structures presented in Table 4 display more than two hydrogen bonds, which were frequently involved in cooperative or chelated systems. In pairs $(\mathbf{1 0 4 , 1 0 5 )}, \mathbf{( 1 0 7 , 1 1 4 ) , ~ a n d ~}$ $(\mathbf{1 1 5}, \mathbf{1 2 1})$, the additional hydroxyl group of the more substituted molecule "benefits" from the electrons of the same carbonyl oxygen as the first one, which weakens the HB to approximately $1 \mathrm{kcal}$.

Interestingly, polyfunctional anhydrofulvic acid 119 (Figure 5) is characterized by a planar structure, which can simultaneously form two strong $\mathrm{O}-\mathrm{H} \cdots \mathrm{O}=\mathrm{C}$ bonds and one $\mathrm{O}-\mathrm{H} \cdots \mathrm{O}-\mathrm{C}_{\text {ar }}$ weak bond in a cooperative hydrogen bonds system. The strongest, with $\mathrm{E}_{\mathrm{HB}}=15.4 \mathrm{kcal} / \mathrm{mol}$, is not a representative bonding of a phenolic group with carbonyl, due to the fact that it is very short (1.469 $\AA$ ), it has an extremely long $\mathrm{O}-\mathrm{H}$ covalent bond $\left(1.017 \AA\right.$ ), a significant redshift of $v_{\mathrm{OH}}$ (to $2745 \mathrm{~cm}^{-1}$ ), the highest chemical shift $\delta_{\mathrm{H}}(16.93 \mathrm{ppm})$, extreme topological parameters at critical points, and is deprived of the quasiaromaticity (quasiHOMA $=-0.263$ ) (see Table S1). The reason for such unusual growth of HB energy is the carboxylic group, which forms a seven-membered, extremely short (1.400 $\AA$ ), and very strong $(14.3 \mathrm{kcal} / \mathrm{mol})$ hydrogen bond, with the carbonyl oxygen atom of partially-coupled pyranone. Moreover, both HBs are supported by the five-membered weak O-H $\cdots \mathrm{O}-\mathrm{C}_{\text {ar }}$ bond. The unusually long (1.51 $\AA$ ) spacer (C-C bond) of the carboxylic group with the aromatic ring (1.47 $\AA$ for 71 acid) should be noted. In this situation the discussed hydrogen bonding can be better described by topological indices (for example the electron density in RCP, see Supplementary Materials, Table S1) than by the HOMA index, and treated rather as the (-)CAHB related feature [72].
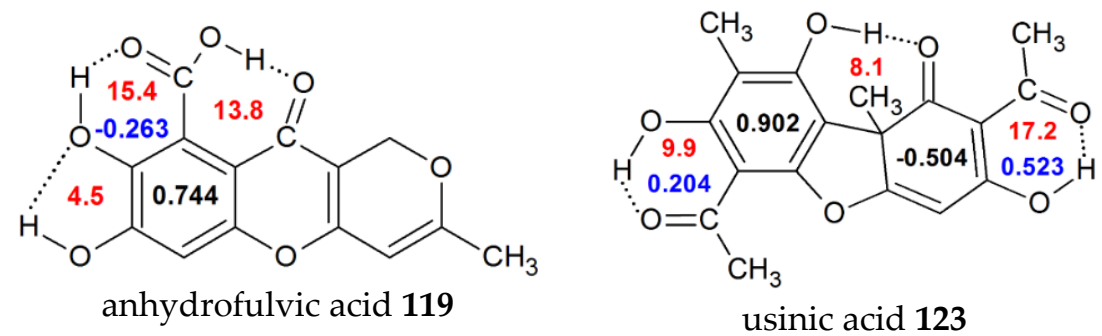

Figure 5. The energies, harmonic oscillator model of aromaticity HOMA and quasiHOMA indices for stable conformers of anhydrofulvic acid 119 (top) and usinic acid 123 (bottom). Values of quasiHOMA (in blue) and $\mathrm{E}_{\mathrm{HB}}$ (in red) were given in the centre of the hydrogen bonded ring, whereas the HOMA value was given in the ipso-ring.

In the study regarding intramolecular hydrogen bonding in naturally-occurring phenolic compounds several structures with seven- or eight-membered rings were also evaluated. Usinic acid 123 (Figure 5) is an example in which three individual hydrogen bonds are isolated: (1) as in ortho-hydroxyacetophenone 2 (Table 1) of $9.9 \mathrm{kcal} / \mathrm{mol}$; (2) a typical strong RAHB of $17.2 \mathrm{kcal} / \mathrm{mol}$ [25]; and (3) the uncoupled seven-membered H-bonding with $\mathrm{E}_{\mathrm{HB}}$ of $8.1 \mathrm{kcal} / \mathrm{mol}$ equal to nearly half of the RAHB energy.

Some of the examined compounds with the phenolic group participating in the seven- or eight-membered rings of intramolecular hydrogen bonding, which are structurally different from the discussed structures, are listed below. They are as follows: 2,3-di(2-hydroxyphenyl)cycloprop2-en-2-one 124; 2-(2-hydroxyphenyl)-1,4-benzoquinone 125; (2-hydroxyphenyl)acetaldehyde 126; (2-hydroxyphenyl)propanone 127; (Z)-2-hydroxycinnamic acid 128; and 2,4-bis[4-(N,N-diethylamino)2,6-dihydroxyphen-yl]squaraine 129. Their important parameters are presented at the end of Table S1. They were not excluded from the regression analysis of the completed parameters (Figure 6).

The geometrical and topological parameters designed to describe and measure the strength of intramolecular hydrogen bonding are as follows: the length of $\mathrm{O}-\mathrm{H} \cdots \mathrm{O}=\mathrm{C}$ bond $\left(\mathrm{r}_{\mathrm{HB}}\right)$, the $\mathrm{HB}$ angle $\left(\varnothing_{\mathrm{HB}}\right)$, the $\mathrm{O} \cdots \mathrm{O}$ distance $\left(\mathrm{d}_{\mathrm{O}} \cdots \mathrm{O}\right)$, the length of oxygen-hydrogen covalent bond $\left(\mathrm{d}_{\mathrm{OH}}\right)$, the frequency of $\mathrm{O}-\mathrm{H}$ stretching $\left(v_{\mathrm{OH}}\right)$ and $\mathrm{C}=\mathrm{O}$ stretching $\left(v_{\mathrm{C}=\mathrm{O}}\right)$, the electron density in the hydrogen bond critical point $\left(\rho_{\mathrm{BCP}}\right)$, its Laplacian $\left(\nabla^{2} \rho_{\mathrm{BCP}}\right)$, the value of potential energy density $\left(\mathrm{V}_{\mathrm{BCP}}\right)$, the electron density in the ring critical point $\left(\rho_{\mathrm{RCP}}\right)$, the chemical shift $\left(\delta_{\mathrm{H}}\right)$, and the HOMA indices: in the ipso-ring 
(HOMA), and in the hydrogen bonded quasiaromatic ring (quasiHOMA). All of the parameters were collected in Table S1 (Supplementary Materials). Satisfying correlations between hydrogen bond energy $\mathrm{E}_{\mathrm{HB}}$ and most of the listed parameters were found, and the best matches are presented in Figure 6.

It can be seen, in Figure 6, that there is a relatively good correlation for the majority of the studied structures, with the exception of $\mathbf{1 1 9}$ and $\mathbf{1 2 3}$ (discussed above), which are characterized by the strongest $\mathrm{H}$ bonding, as well as structures with a weak $\mathrm{H}$ bonding: 7-hydroxy-1-indanone 62, salfredin 103,1-hydroxyfluorenone 105, and 1,8-dihydroxyfluorenone 104. The last four compounds have the $\mathrm{H}$-bonding systems stiffened by external five-membered rings, therefore, they do not match the main trend due to the geometric constraints of HB (see Supplementary Materials, Figure S1, structure 62).
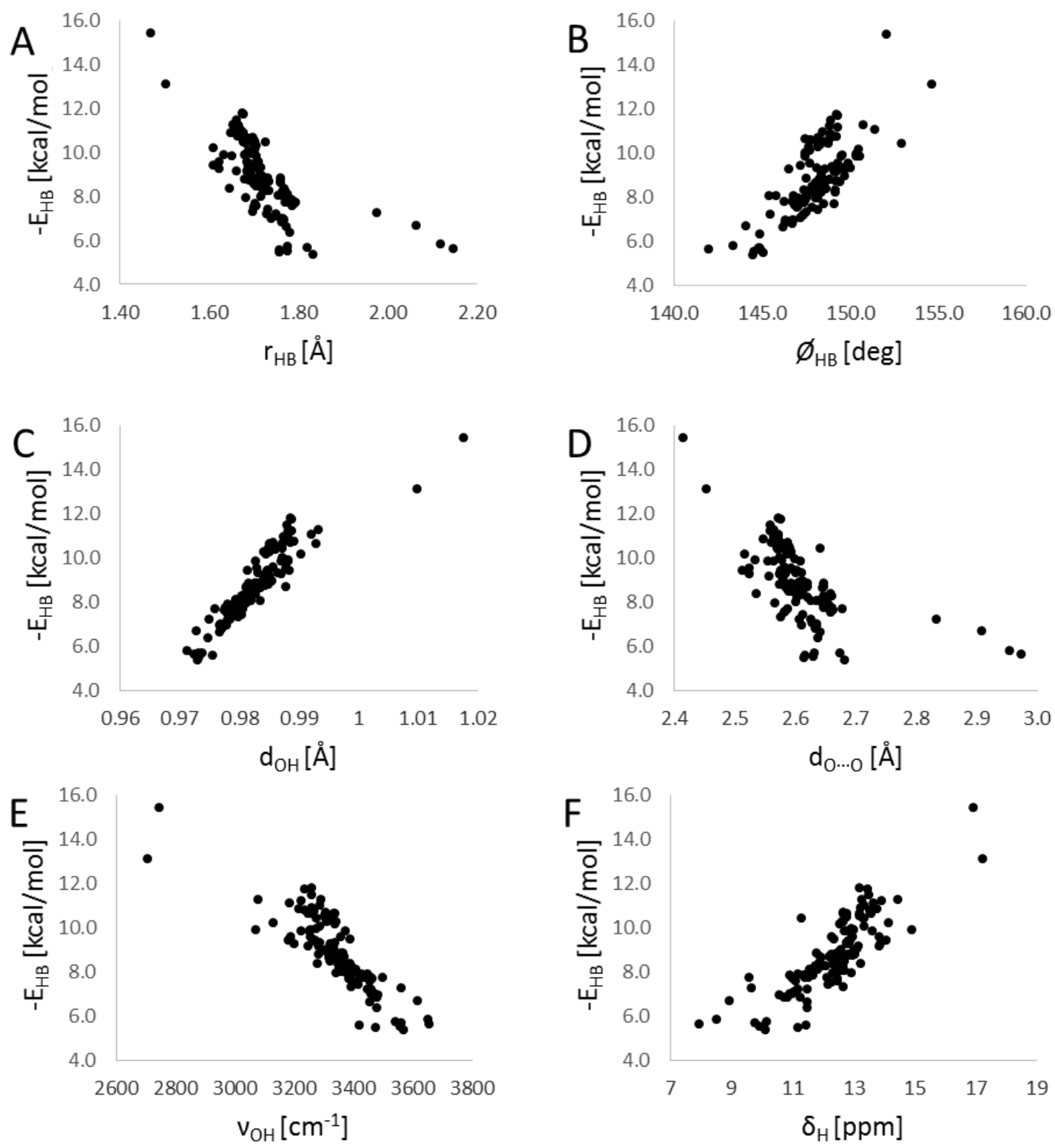

Figure 6. Cont. 

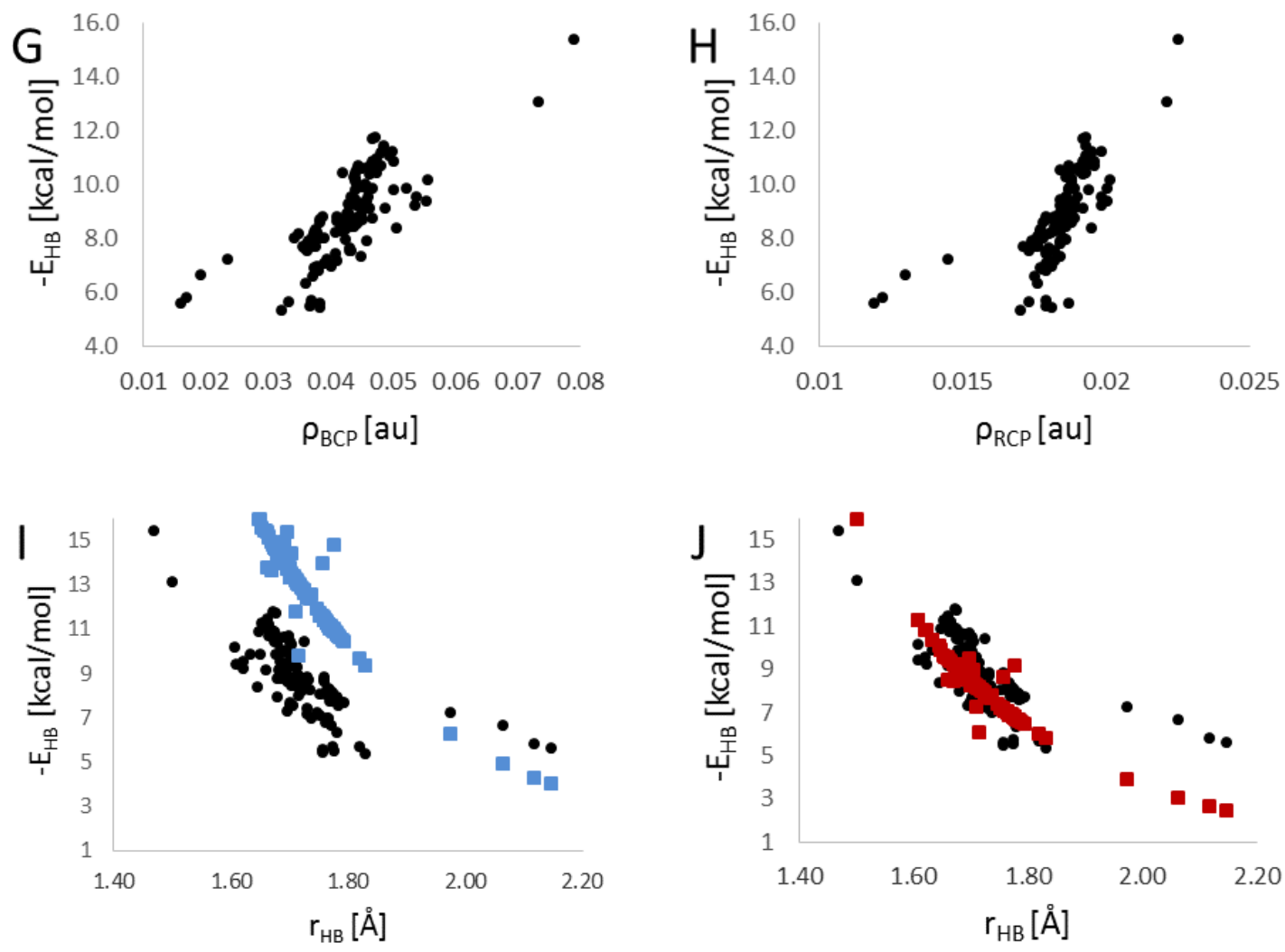

Figure 6. The relations between the calculated energy of intramolecular hydrogen bond $\mathrm{E}_{\mathrm{HB}}(\mathrm{kcal} / \mathrm{mol})$ and some geometrical, spectral and topological parameters of one hundred twenty five investigated hydroxycarbonyl compounds : (A) length of $\mathrm{H}$ bonding $\mathrm{r}_{\mathrm{HB}}(\AA)$; (B) angle of $\mathrm{O}-\mathrm{H} \cdots \mathrm{O} \varnothing_{\mathrm{HB}}(\mathrm{deg})$; (C) length of $\mathrm{O}-\mathrm{H}$ bond $\mathrm{d}_{\mathrm{OH}}(\AA)$; (D) $\mathrm{O} \cdots \mathrm{O}$ distance $\mathrm{d}_{\mathrm{O}} \cdots \mathrm{O}(\AA)$; (E) frequency of $\mathrm{O}-\mathrm{H} v_{\mathrm{OH}}\left(\mathrm{cm}^{-1}\right)$; (F) chemical shift of $\mathrm{O}-\mathrm{H}$ hydrogen $\delta_{\mathrm{H}}(\mathrm{ppm}),(\mathrm{G})$ electron density in hydrogen bond critical point $\rho_{\mathrm{BCP}}(\mathrm{au}) ;(\mathbf{H})$ electron density in ring critical point $\rho_{\mathrm{RCP}}(\mathrm{au}) ;(\mathbf{I})$ comparison of $\mathrm{E}_{\mathrm{HB}}$ values calculated in the framework of this study and $E_{\mathrm{HB}}$ calculated based on Espinosas' equation $\left(E_{H B}=\frac{1}{2} V_{B C P}\right)$ [27] in relation to length of $\mathrm{H}$ bonding $\mathrm{r}_{\mathrm{HB}}(\AA) ;(J)$ comparison of $\mathrm{E}_{\mathrm{HB}}$ values calculated in the framework of this study and $E_{H B}$ calculated based on Afonins' equation $\left(E_{H B}=0.31 \times V_{B C P}\right)$ [28] in relation to length of $\mathrm{H}$ bonding $\mathrm{r}_{\mathrm{HB}}(\AA)$.

The best correlations were established between the energy of the intramolecular $\mathrm{H}$ bond and the length of the covalent $\mathrm{O}-\mathrm{H}$ bond, as well as the frequency of $\mathrm{O}-\mathrm{H}$ stretching. These parameters may be safely employed for estimation of the strength of HB. The NMR chemical shift values (empirical or calculated) of the analysed structures, which are often successfully used to compare the strength of HB $[28,73]$, were mostly similar with the results obtained in our study (Supplementary Materials, Table S1) and may be correlated with the rest of typical parameters used in HB examination. The values of HOMA were within a range of 0.504 to 0.978 , whereas quasiHOMA ranged from -0.236 to 0.543 , but they were not sufficiently correlated with $\mathrm{E}_{\mathrm{HB}}$ (see Supplementary Materials, Figure S2).

\section{Summary and Discussion}

The problem associated with quantitative measurements of the strength of intramolecular hydrogen bonding energy is widely recognized. However, it has not been definitively resolved to date. Our previous studies were focused on an attempt to take advantage of the computational method of the molecular tailoring approach (MTA), which has been previously proposed and applied for hydrogen bonds in hydroxy-hydroxy or hydroxy-alkoxy systems by [18]. This method is based on quantum chemistry calculations of the energy of molecules as a sum of their smaller fragments. 
When the molecule is entangled in the intramolecular hydrogen bond and "this internal HB can be broken without causing other structural or electronic changes" [11], as in the MTA method, the calculations are possible for each combination of $\mathrm{O}-\mathrm{H}$ as a donor, and $\mathrm{O}=\mathrm{C}$ as an acceptor, of $\mathrm{HB}$. When the donor, the acceptor, and both are replaced by the hydrogen atom in the same molecule, their energies may be summarized and compared with the energy calculated for the whole molecule [30]. The conditions which are necessary for the success of this method include preliminary optimization of the molecule, appropriate incision of the system, and no intervention in geometry after insertion of hydrogen atoms. This method has been previously checked for many hydrogen bonds present in hydroxycarbonyl compounds with the full possibility of rotation (saturated) or with some restraints (double bond, ring) [30] and recently, for several structures with resonance-assisted hydrogen bond (RAHB) [25], good accuracy, repeatability, and applicability have been found.

As mentioned in the paragraph following Table 1, the $\mathrm{E}_{\mathrm{HB}}$ values presented in the literature by different methods are divergent. The most widely used method (cis-trans, syn-anti, open-close) is based on the comparison of energies of two conformers: one involved in the intramolecular $\mathrm{HB}$, and the second one in which this bond is broken by the rotation of the proton donor $\mathrm{OH}$ group outside of the carbonyl acceptor. This method is flawed because it does not include the repulsion of both oxygen atoms. It cannot be used for more complex compounds with more than one HB and with the steric hindrance of the rotated $\mathrm{OH}$ group. The results are mostly overestimated, in some cases even up to two times [16,44,54,59].

When experimental or calculated parameters (length of hydrogen bonds, the O-H covalent bond length, the $\mathrm{O} \cdots \mathrm{O}$ distance, IR frequencies, NMR chemical shifts) have been included in the estimation $[56,62,63,69,73]$, the $\mathrm{E}_{\mathrm{HB} \text { cis-trans }}$ values are smaller and similar to those obtained in this study. Although the isodesmic approach results in values similar to those obtained in the framework of this study, their use for estimating the HB energy in such complicated structures is not recommended. This method is advocated for systems with one $\mathrm{HB}$, but is not recommended for the estimation of the single intramolecular H-bond energy in polyhydroxy systems [17]. Values of interaction energies obtained by means of isodesmic reactions seem to be more reliable if they concern planar molecules [18]. Over the last two decades, the methods based on the AIM electron density parameters, which may be measured for covalent bonds, for hydrogen bonds, and for aromatic rings, have been considered as advantageous. The EHB energy can also be calculated on the basis of the potential energy density $\mathrm{V}_{\mathrm{BCP}}$ by Espinosa's [27] equation, which was recently examined in detail and modified by Afonin [28] using new linear regression coefficients.

Energies of intramolecular H-bonds presented in this study comply well with the values calculated based on Espinoza's equation modified by Afonin $\left(E_{H B}=0.31 \times V_{B C P}\right)$ [28] (see Figure 6J).

In the presented work, the MTA method was used to analyse the hydrogen bonding and to calculate HB energy for phenols (hydroxyphenyl group as a proton donor) and miscellaneous carbonyl spacers. Almost 140 structures of hydroxyaromatic aldehydes, ketones, acids, esters, amides, quinones, and anthraquinones were optimized at the MP2(FC)/6-311++G(2d,2p) level, then cut into appropriate fragments and $E_{H B}$ calculated with the MTA method. The results obtained for simple phenolic, substituted, and more elaborate structures can be arranged in a sequence congruent with geometrical, spectral, and topological indicators of the hydrogen bonding strength. The MTA energies of the intramolecular hydrogen bond between phenolic hydrogen and carbonyl groups in the six-membered ring are in the range of 5.4 to $15.4 \mathrm{kcal} / \mathrm{mol}$. When the phenolic group participates as a donor in sevenor eight-membered $\mathrm{HB}$ rings, the $\mathrm{E}_{\mathrm{HB}}$ typically ranges from 4.6 to $9.6 \mathrm{kcal} / \mathrm{mol}$, and does not differ from values obtained for saturated carbonyl substituted alcohols.

For all H-bonded phenolic structures, the HOMA indices of aromaticity were calculated for the ipso-rings [12], while quasiHOMA indices were calculated for the H-bonded rings. Changes of both parameters associated with substitution in the ipso-ring and elsewhere, as well as the effects of cooperation and/or chelation of HB were observed, and it was noticed that quasiHOMA varied from negative values to 0.543 , whereas HOMA ranged from 0.503 to 0.978 , but they were not 
correlated with $\mathrm{E}_{\mathrm{HB}}$. This is not surprising, because this parameter was calculated according to Equation (2) on the basis of the length of four bonds: $C_{a r}-O, C_{a r}-C_{a r}, C_{a r}-C(=O)$, and $C=O$, and does not specify the position of the $\mathrm{H}$-bonded hydrogen atom. In some of the analyzed structures important regularity was found. The presented pairs of tautomers of triformylphloroglucinol 44 and 2,4,6-tri(hydroxymethylindene)cyclohexa-1,3,5-trione 44T, as well as triacetylophloroglucine 70 and triacetophen 70T, evidently showed that total resonance stabilization energy is defined and limited by the heavy atom frame of the molecule. The transfer of phenolic protons (within the frame) leads to the formation of a related tautomer which differs-by definition-in terms of the localization of acidic (i.e., phenolic or enolic) protons and, consequently, the pattern of carbon-carbon double bonds. The tautomerization of aromatic derivative due to inter alia $\pi$-electron transfer generally canceled the aromaticity of the central ring, but its resonance energy transfers outside this ring-into its rearranged, but still H-bonded substituents-organized into three external rings.

Similarly, the analysis of hydrogen bonding of 1,4-benzoquinone derivatives and their tautomers (pairs 83 and 83T, and 97 and 97T) led to a similar picture of the redistribution of $\pi$-delocalization from benzene into HB rings (Figures 3 and 5) which was manifested by the decrease of HOMA indices and a notable increase of quasiHOMA and $\mathrm{E}_{\mathrm{HB}}$ values. The phenomenon of transfer of aromaticity can be rationalized in terms of the number of $\pi$-electrons counted for each ring: in Figure 4 structure 97 of quinizarin has two benzenoid rings with six $\pi$-electrons each, thus, being fully aromatic according to the Hückel rule, and a central ring with only four $\pi$-electron is not aromatic. It is, thus, not unexpected that the HOMA indices of the first are 0.872 and 0.970 , while for the last a value of -0.205 is found. On passing for the structure 97T a ring with six $\pi$-electrons is maintained, with a HOMA value of 0.950, but now the other benzenoid ring has only five $\pi$-electrons and its HOMA is, accordingly, 0.420. On this hand the central ring, also with five $\pi$-electrons, has a quasiHOMA value of 0.132 .

The calculation of HOMA and quasiHOMA indicated that spectacular losses of resonance energy in the aromatic ring was found as a result of the large increase of concomitant quasiaromaticity of the two rearranged hydrogen bonding systems present. In other words, the $\mathrm{E}_{\mathrm{HB}}$ values typical for very strong RAHB hydrogen bonds and appreciable quasiHOMA values confirmed the origin of the reduced HOMA values of the enolic tautomer.

Finally, this study shows that introduction of the energy of hydrogen bonds calculated based on the MTA method as the parameter characterizing the molecular system reveals new possibilities for the interpretation of the associated resonance-assisted phenomena.

Supplementary Materials: The following are available online at www.mdpi.com/1420-3049/22/3/481/s1, Figure S1: Examples of MTA fragmentation employed for selected structures analyzed in the study. Different colors represent different fragmentation of different intramolecular hydrogen bonds, Figure S2: MTA Intramolecular Hydrogen Bond Energy [kcal/mol] as a Function of Laplacian of the Electron Density in the Bond Critical Point [au] (A) and its HOMA Index (B) for Structures with Phenolic Intramolecular Hydrogen Bonding, Table S1: MTA Energy of Intramolecular Hydrogen Bonding EHB [kcal/mol], Length of the HB as $\mathrm{H} \cdots \mathrm{O}\left(\mathrm{r}_{\mathrm{HB}}\right)[\mathrm{A}]$, Angle of the $\mathrm{HB}$ as $\mathrm{O}-\mathrm{H} \cdots \mathrm{O}\left(\phi_{\mathrm{HB}}\right)[\mathrm{deg}]$, Length of the $\mathrm{O}-\mathrm{H}$ Bond $\left(\mathrm{d}_{\mathrm{OH}}\right)[\mathrm{A}]$, Distance Between the Oxygen Atoms as $\mathrm{O} \cdots \mathrm{O}\left(\mathrm{d}_{\mathrm{O}} \cdots \mathrm{O}\right)[\mathrm{A}]$, Frequency of $\mathrm{O}-\mathrm{H}$ and $\mathrm{C}=\mathrm{O}$ Stretching $\left[\mathrm{cm}^{-1}\right]$, HNMR Chemical Shifts $\delta_{\mathrm{H}}$ [ppm], Electron Density in the Bond Critical Point $\left(\rho_{\mathrm{BCP}}\right)[\mathrm{au}]$ and its Laplacian $\left(\nabla^{2} \rho_{\mathrm{BCP}}\right)$, the value of Potential Energy Density $\left(\mathrm{V}_{\mathrm{BCP}}\right)$, Electron Density in the Ring Critical Point $\left(\rho_{\mathrm{RCP}}\right)[\mathrm{au}]$ and HOMA and quasiHOMA Indices Calculated for Structures 1 - 129. Structures 44T, 70T, 83T and 97T serve to compare them with 44, 70, 83, 97 because they not present phenolic type of HB.

Acknowledgments: This study was supported by Poznan University of Technology 03/32/DSPB/0700. The authors also acknowledge Poznanskie Centrum Superkomputerowo-Sieciowe, Poznan, Poland, for computational time. The author would like to express gratitude to Marek Lozynski from Poznan University of Technology for insightful discussion during the preparation of the manuscript.

Conflicts of Interest: The author declares no conflict of interest.

\section{References}

1. Jeffrey, G.A.; Saenger, W. Hydrogen Bonding in Biological Structures; Springer-Verlag: Berlin, Germany, 1994. 
2. Desiraju, G.; Steiner, T. The Weak Hydrogen Bond-In Structural Chemistry and Biology; Oxford University Press: New York, NY, USA, 1999.

3. Bilton, C.; Allen, F.H.; Shields, G.P.; Howard, J.A.K. Intramolecular Hydrogen Bonds: Common Motifs, Probabilities of Formation and Implications for Supramolecular Organization. Acta Crystallogr. 2000, B56, 849-856. [CrossRef] [PubMed]

4. Gilli, G.; Bellucci, F.; Ferretti, V.; Bertolasi, V. Evidence for Resonance-Assisted Hydrogen Bonding from Crystal-Structure Correlations on the Enol form of the $\beta$-Diketone Fragment. J. Am. Chem. Soc. 1989, 111, 1023-1028. [CrossRef]

5. Gilli, P.; Bertolasi, V.; Ferretti, V.; Gilli, G. Covalent Nature of the Strong Homonuclear Hydrogen Bond. Study of the O-H...O System by Crystal Structure Correlation Methods. J. Am. Chem. Soc. 1994, 116, 909-915. [CrossRef]

6. Gilli, G.; Gilli, P. The Nature of the Hydrogen Bond-Outline of a Comprehensive Hydrogen Bond Theory; Oxford University Press: New York, NY, USA, 2009.

7. Scheiner, S. Relative Strengths of $\mathrm{NH} \cdots \mathrm{O}$ and $\mathrm{CH} \cdots \mathrm{O}$ Hydrogen Bonds between Polypeptide Chain Segment. J. Phys. Chem. B 2005, 109, 16132-16141. [CrossRef] [PubMed]

8. Scheiner, S.; Kar, T. Red- versus Blue-Shifting Hydrogen Bonds: Are there Fundamental Distinctions? J. Phys. Chem. A 2002, 106, 1784-1789. [CrossRef]

9. Sigalov, M.V.; Doronina, E.P.; Sidorkin, V.F. $\mathrm{C}_{\mathrm{Ar}}-\mathrm{H} \cdots \mathrm{O}$ Hydrogen Bonds in Substituted Isobenzofuranone Derivatives: Geometric, Topological, and NMR Characterization. J. Phys. Chem. A 2012, 116, 7718-7725. [CrossRef] [PubMed]

10. Sobczyk, L.; Grabowski, S.J.; Krygowski, T.M. Interrelation between H-Bond and Pi-Electron Delocalization. Chem. Rev. 2005, 105, 3513-3560. [CrossRef] [PubMed]

11. Scheiner, S. Assessment of the Presence and Strangth of H-Bonds By Means of Corrected NMR. Molecules 2016, 21, 1426. [CrossRef] [PubMed]

12. Krygowski, T.M.; Zachara, J.E.; Ośmiałowski, B.; Gawinecki, R. Topology-Driven Physicochemical Properties of $\pi$-Electron Systems. 1. Does the Clar Rule Work in Cyclic $\pi$-Electron Systems with the Intramolecular Hydrogen or Lithium Bond? J. Org. Chem. 2006, 71, 7678-7682. [CrossRef] [PubMed]

13. Grabowski, S.J. Hydrogen Bonding Strength-Measures Based on Geometrical and Topological Parameters. J. Phys. Org. Chem. 2004, 17, 18-31. [CrossRef]

14. Jabłoński, M. Energetic and Geometrical Evidence of Nonbonding Character of Some Intramolecular Halogen ..Oxygen and Other Y..Y Interactions. J. Phys. Chem. A 2012, 116, 3753-3764. [CrossRef] [PubMed]

15. Parra, R.D.; Ohlssen, J. Cooperativity in Intramolecular Bifurcated Hydrogen Bonds: An Ab Initio Study. J. Phys. Chem. A 2008, 112, 3492-3498. [CrossRef] [PubMed]

16. Jabłoński, M. Full vs. Constrain Geometry Optimization in the Open-closed Method in Estimating the Energy of Intramolecular Charge-inverted Hydrogen Bonds. Chem. Phys. 2010, 376, 76-83. [CrossRef]

17. Deshmukh, M.M.; Suresh, C.H.; Gadre, S.R. Intramolecular Hydrogen Bond Energy in Polyhydroxy Systems: A Critical Comparison of Molecular Tailoring and Isodesmic Approaches. J. Phys. Chem. A 2007, 111, 6472-6480. [CrossRef] [PubMed]

18. Jabłoński, M.; Monaco, G. Different Zeroes of Interaction Energies as the Cause of Opposite Results on the Stabilizing Nature of $\mathrm{C}-\mathrm{H} \cdots \mathrm{O}$ Intramolecular Interaction. J. Chem. Inf. Model. 2013, 53, 1661-1675. [CrossRef] [PubMed]

19. Rozas, I. On the Nature of Hydrogen Bonds: An Overview on Computational Studies and a Word about Patterns. Phys. Chem. Chem. Phys. 2007, 9, 2782-2790. [CrossRef] [PubMed]

20. Fuster, F.; Grabowski, S.J. Intramolecular Hydrogen Bonds: the QTAIM and ELF Characteristics. J. Phys. Chem. A 2011, 115, 10078-10086. [CrossRef] [PubMed]

21. Deshmukh, M.M.; Gadre, S.R.; Bartolotti, L.J. Estimation of Intramolecular Hydrogen Bond Energy via Molecular Tailoring Approach. J. Phys. Chem. A 2006, 110, 12519-12523. [CrossRef] [PubMed]

22. Mo, Y. Can QTAIM Topological Parameters Be a Measure of Hydrogen Bonding Strength? J. Phys. Chem. A 2012, 116, 5240-5246. [CrossRef] [PubMed]

23. Parra, R.D.; Streu, K. Cooperative Effects in Regular and Bifurcated Intramolecular OH $\cdots \mathrm{O}=\mathrm{C}$ Interactions: A Computational Study. Comput. Theor. Chem. 2011, 977, 181-187. [CrossRef]

24. Grabowski, S.J. п-Electron Delocalisation for Intramolecular Resonance Assisted Hydrogen Bonds. J. Phys. Org. Chem. 2003, 16, 797-802. [CrossRef] 
25. Rusinska-Roszak, D. Intramolecular $\mathrm{O}-\mathrm{H} \cdots \mathrm{O}=\mathrm{C}$ Hydrogen Bond Energy via the Molecular Tailoring Approach to RAHB Structures. J. Phys. Chem. A 2015, 119, 3674-3687. [CrossRef] [PubMed]

26. Palusiak, M.; Krygowski, T.M. Application of AIM Parameters at Ring Critical Points for Estimation of $\pi$-Electron Delocalization in Six-Membered Aromatic and Quasi-Aromatic Rings. Chem. Eur. J. 2007, 13, 7996-8006. [CrossRef] [PubMed]

27. Espinosa, E.; Molins, E.; Lecomte, C. Hydrogen Bond Strenght Revealed by Topological Analyses of Experimentally Observed Electron Densities. Chem. Phys. Lett. 1998, 285, 170-173. [CrossRef]

28. Afonin, A.V.; Vashchenko, A.V.; Sigalov, M.V. Estimating the Energy of Intramolecular Hydrogen Bonds from ${ }^{1} \mathrm{H}$ NMR and QTAIM Calculations. Org. Biomol. Chem. 2016, 14, 11199-11211. [CrossRef] [PubMed]

29. Gadre, S.R.; Shirsat, R.N.; Limaye, A.C. Molecular Tailoring Approach for Simulation of Electrostatic Properties. J. Phys. Chem. 1994, 98, 9165-9169. [CrossRef]

30. Rusinska-Roszak, D.; Sowinski, G. Estimation of the Intramolecular O-H $\cdots \mathrm{O}=\mathrm{C}$ Hydrogen Bond Energy via the Molecular Tailoring Approach: Part I Aliphatic Structures. J. Chem. Inf. Model. 2014, 54, 1963-1977. [CrossRef] [PubMed]

31. Alvareda, E.; Denis, P.A.; Iribarne, F.; Paulino, M. Bond Dissociation Energies and Enthalpies of Formation of Flavonoids: A G4 and 06-2X Investigation. Comput. Theor. Chem. 2016, 1091, 18-23. [CrossRef]

32. Mammino, L.; Kabanda, M.M. A Computational Study of the Effects of Different Solvents on the Characteristics of the Intramolecular Hydrogen Bond in Acylphloroglucinols. J. Phys. Chem. A 2009, 113, 15064-15077. [CrossRef] [PubMed]

33. Mammino, L.; Kabanda, M.M. Computational Study of the Patterns of Weaker Computational Intramolecular Hydrogen Bond Stabilizing Acylphloroglucinols. Int. J. Quantum Chem. 2012, 112, 2650-2658. [CrossRef]

34. Galasso, V. Probing the Molecular and Electronic Structure of the Lichen Metabolite Usinic Acid: A DFT Study. Chem. Phys. 2010, 374, 138-145. [CrossRef]

35. Zheng, Y.-J.; Basarab, G.S.; Jordan, D.B. Roles of Substrate Distortion and Intramolecular Hydrogen Bonding in Enzymatic Catalysis by Scytalone Dehydratase. Biochemistry 2002, 41, 820-826. [CrossRef] [PubMed]

36. Da Rocha, D.R.; de Souza, A.C.G.; Resende, J.A.L.C.; Santos, W.C.; dos Santos, E.A.; Pessoa, C.; de Moraes, M.O.; Costa-Lotufo, L.V.; Montenegro, R.C.; Vereira, V.F. Synthesis of New 9-hydroxy- $\alpha$ - and 7-hydroxy- $\beta$-pyranNaphtoquinones and Cytotoxicity against Cancer Cell Lines. Org. Biomol. Chem. 2011, 9 , 4315-4322. [CrossRef] [PubMed]

37. Musin, R.N.; Mariam, Y.H. An Integrated Approach to the Study of Intramolecular Hydrogen Bonds in Malonaldehyde Enol Derivatives and Naphtharizin: Trend in Energetic versus Geometrical Consequences. J. Phys. Org. Chem. 2006, 19, 425-444. [CrossRef]

38. Jacquemin, D.; Brémond, E.; Planchat, A.; Ciofini, I.; Adamo, C. TD-DFT Vibronic Couplings in Anthraquinones: From Basis Set and Functional Benchmarks to Applications for Industrial Dyes. J. Chem. Theory Comput. 2011, 7, 1882-1892. [CrossRef] [PubMed]

39. Palusiak, M.; Simon, S.; Sola, M. Interplay between Intramolecular Resonance-Assisted Hydrogen Bonding and Aromaticity in o-Hydroxyaryl Aldehydes. J. Org. Chem. 2006, 71, 5241-5248. [CrossRef] [PubMed]

40. Lenain, P.; Mandado, M.; Mosquera, R.A.; Bultinck, P. Interplay between Hydrogen-Bond formation and Multicenter $\pi$-Electron Delocalization: Intramolecular Hydrogen Bonds. J. Phys. Chem. A 2008, 112, 10689-10696. [CrossRef] [PubMed]

41. Becke, A.D. Density-Functional Thermochemistry. III. The Role of Exact Exchange. J. Chem. Phys. 1993, 98, 5648-5652. [CrossRef]

42. Lee, C.; Yang, W.; Parr, R.G. Development of the Colle-Salvetti Correlation-Energy Formula into a Functional of the Electron Density. Phys. Rev. B 1988, 37, 785-789. [CrossRef]

43. Frisch, M.J.; Trucks, G.W.; Schlegel, H.B.; Scuseria, G.E.; Robb, M.A.; Cheeseman, J.R.; Scalmani, G.; Barone, V.; Mennucci, B.; Petersson, G.A.; et al. Gaussian 09; Revision B.01; Gaussian, Inc.: Wallingford, TC, USA, 2010.

44. Catalán, J.; Palomar, J.; de Paz, J.L.G. Intramolecular Proton or Hydrogen-Atom Transfer in the Ground and Excited States of 2-Hydroxybenzoyl Compounds. J. Phys. Chem. A 1997, 101, 7914-7921.

45. Wolinski, K.; Hilton, J.F.; Pulay, P. Efficient Implementation of the Gauge-Independent Atomic Orbital Method for NMR Chemical Shift Calculations. J. Am. Chem. Soc. 1990, 112, 8251-8260. [CrossRef]

46. Biegler-König, F.; Schönbohm, J.; Bayles, D. Software News and Updates AIM2000-A program to Analyze and Visualize Atoms in Molecules. J. Comput. Chem. 2001, 22, 545-559.

47. Keith, T.A. AIMAll; Version 13.01.27; TK Gristmill Software: Overland Park, KS, USA, 2013. 
48. Palusiak, M.; Simon, S.; Sola, M. Interplay between Intramolecular Resonance-Assisted Hydrogen Bonding and Local Aromaticity. II. 1,3-Dihydroxyaryl-2-Aldehydes. J. Org Chem. 2009, 74, 2059-2066. [CrossRef] [PubMed]

49. Jezierska-Mazzarello, A.; Panek, J.J.; Szatyłowicz, H.; Krygowski, T.M. Hydrogen Bonding as A Modulator of Aromaticity and Electronic Structure of Selected ortho-Hydroxybenzaldehyde Derivatives. J. Phys. Chem. A 2012, 116, 460-475. [CrossRef] [PubMed]

50. Krygowski, T.M. Crystallographic Studies of Inter- and Intramolecular Interactions Reflected In Aromatic Character of $\pi$-Electron Systems. J. Chem. Inf. Comput. Sci. 1993, 33, 70-78. [CrossRef]

51. Krygowski, T.M.; Cyrański, M.K. Two Faces of the Structural Aspects of Aromaticity. Phys. Chem. Chem. Phys. 2004, 6, 249-255. [CrossRef]

52. Krygowski, T.M.; Cyrański, M. Separation of the Energetic and Geometric Contributions to the Aromaticity of $\pi$-Electron Carbocyclics. Tetrahedron 1996, 52, 1713-1722. [CrossRef]

53. Jezierska-Mazzarello, A.; Szatyłowicz, H.; Krygowski, T.M. Interference of H-Bonding and Subsituent Effects in Nitro- and Hydroxy-Substituted Salicylaldehydes. J. Mol. Model. 2012, 18, 127-135. [CrossRef] [PubMed]

54. Ebrahimi, A.; Khorasani, S.M.H.; Neyband, R.S. The O $\cdots H$ Intramolecular Hydrogen Bond in 4-X-Hydroxybenzaldehydes: The Relationships Between Geometrical Parameters, Estimated Binding Energies, and NMR Data. Int. J. Quantum Chem. 2010, 110, 1871-1879. [CrossRef]

55. Grabowski, S.J. Properties of a Ring Critical Points Measures of Intramolecular H-Bond Strength. Monatsh. Chem. 2002, 133, 1373-1380. [CrossRef]

56. Lapinski, L.; Rostkowska, H.; Reva, I.; Fausto, R.; Nowak, M.J. Positive Identification of UV-Generated, Non-Hydrogen-Bonded Isomers of $o$-Hydroxybenzaldehyde and $o$-Hydroxyacetophenone. J. Phys. Chem. A 2010, 114, 5588-5595. [CrossRef] [PubMed]

57. Fedorov, E.E.; Makarov, O.E.; Pankratov, A.N.; Grinev, V.S. Gas-Liquid Chromatography-Obtained Differences In the Dissolution Enthalpy between Two Positional Isomers in a Polar Stationary Phase: A Measure of the Inter- or Intramolecular Hydrogen Bond Energy? J. Chromatogr. A 2012, 1241, 76-83. [CrossRef] [PubMed]

58. Zhang, Y.; Wang, C.-S. Estimation on Intramolecular Hydrogen-Bonding Energy via the Substitution Method JIEGO HUAXUE. Chin. J. Struct. Chem. 2008, 27, 829-835.

59. Ebrahimi, A.; Habibi, S.M.; Neyband, R.S. Substituent Effect on Intramolecular Hydrogen Bonding in 2-Hydroxybenzaldehyde. Int. J. Quantum Chem. 2009, 109, 1274-1282. [CrossRef]

60. Davalos, J.Z.; Guerrero, A.; Herrero, R.; Jimenez, P.; Chana, A.; Abboud, J.L.M.; Lima, C.F.R.A.C.; Santos, L.N.B.F.; Lago, A.F. Neutral, Ion Gas-Phase Energetics and Structural Properties of Hydroxybenzophenones. J. Org. Chem. 2010, 75, 2564-2571. [CrossRef] [PubMed]

61. Ganguly, A.; Paul, B.K.; Ghosh, S.; Guchhait, N. A Computational Acumen into the Relative Applicability of Geometrical and Quantum Chemical Criteria in Assessing Intramolecular Hydrogen Bonding (IMHB) Interaction: 5-Halosalicylic Acids as Representative Examples. Comput. Theor. Chem. 2013, 1018, 103-114. [CrossRef]

62. Shigorin, D.N. Hydrogen Bond in $\pi$-Electron Systems. In Hydrogen Bond; Sokolov, N.D., Chulanovsky, A.D., Eds.; Nauka: Moscow, Russia, 1964; pp. 195-219.

63. Kopteva, T.S.; Shigorin, D.N. Nature of Intramolecular Hydrogen Bonding in Molecules with P-Electrons and Its Effects on the IR Vibrational Spectra. Zh. Fiz. Khim. 1974, 48, 532-536.

64. Lago, A.F.; Jimenez, P.; Herrero, R.; Davalos, J.Z.; Abboud, J.-L.M. Thermochemistry and Gas-Phase Ion Energetics of 2-Hydroxy-4-Methoxy-Benzophenone (Oxybenzone). J. Phys. Chem. A 2008, 112, 3201-3208. [CrossRef] [PubMed]

65. Wiberg, K.B. Application of the Pople-Santry-Segal CNDO Method to the Cyclopropylcarbinyl and Cyclobutyl Cation and to Bicyclobutane. Tetrahedron 1968, 24, 1083-1096. [CrossRef]

66. Randić, M. Aromaticity of Polycyclic Conjugated Hydrocarbons. Chem. Rev. 2003, 103, 3449-3605. [CrossRef] [PubMed]

67. Solà, M. Forty Years of Clar'sAromatic $\pi$-Sekstet Rule. Front. Chem. 2013, 2, 1-8.

68. Ramondo, F.; Bencivenni, L. Ab Initio HF-SCF Study of Naphthazarin: Geometries, Isomerism, Hydrogen Bond, and Vibrational Spectrum. Struct. Chem. 1994, 5, 211-224. [CrossRef] 
69. Zahedi-Tabrizi, M.; Tayyari, S.F.; Tayyari, F.; Behforouz, M. Fourierr Transform Infrared and Raman Spectra, Vibrational Assignment and Density Functional Theory Calculations of Naphthazarin. Spectrochim. Acta. A 2004, 60, 111-120. [CrossRef]

70. Zahedi-Tabrizi, M.; Farahati, R. Calculation of Intramolecular Hydrogen Bonding Strength and Natural Bond Orbital (NBO) Analysis of Naphthazarin with Chlorine Substitution. Comput. Theor. Chem. 2011, 977, 195-200. [CrossRef]

71. Sørensen, J.; Clausen, H.F.; Poulsen, R.D.; Overgaard, J.; Schiøt, B. Short Strong Hydrogen Bonds in 2-Acetyl-1,8-Dihydroxy-3,6-Dimethylnaphthalene: An Outlier to Current Hydrogen Bond Theory? J. Phys. Chem. A 2007, 111, 345-351. [CrossRef] [PubMed]

72. Pakiari, A.H.; Eskandari, K. The Chemical Nature of Very Strong Hydrogen Bonds in Some Categories of Compounds. J. Mol. Struct. (Theochem) 2006, 759, 51-60. [CrossRef]

73. Siskos, M.G.; Tzakos, A.G.; Gerothanassis, I.O. Accurate Ab Initio Calculations of O-H...O and O-H..- $\mathrm{O}$ Proton Chemical Shifts: Towards Elucidation of the Nature of the Hydrogen Bond and Prediction of Hydrogen Bond Distances. Org. Biomol. Chem. 2015, 13, 8852-8868. [CrossRef] [PubMed]

Sample Availability: Coordinates of the compounds 1-129 are available from the author. 